Supporting information for

\title{
"Chiroptical Properties of Indolenine Squaraines with a Stereogenic Center at Close Proximity"
}

Joshua Selby, Marco Holzapfel, Blaise Kimbadi Lombe, David Schmidt, Ana-Maria Krause, Frank Würthner, Gerhard Bringmann, Christoph Lambert*

Institut für Organische Chemie, Universität Würzburg, Am Hubland, 97074 Würzburg, Germany, and Center for Nanosystems Chemistry (CNC), Universität Würzburg, Theodor-Boveri-Weg 9, 97074 Würzburg, Germany.

e-mail: christoph.lambert@uni-wuerzburg.de 


\section{Table of contents}

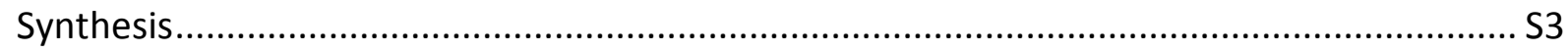

Calculation of the formation probabilities of the stereoisomers of the chiral squaraines . S3

Calculation of the selectivity factor of the kinetic resolution ............................................. S3

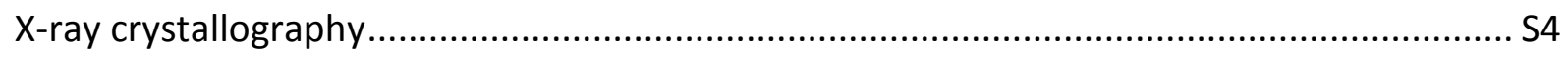

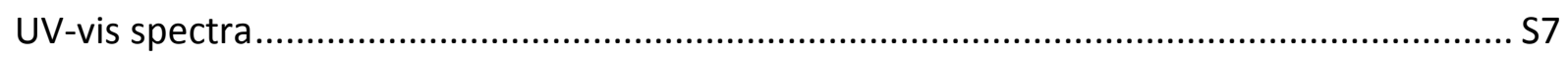

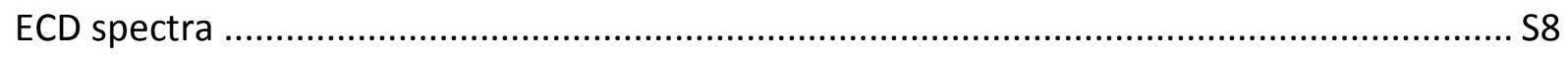

Calculation of transition moments and rotatory strengths ............................................. 99

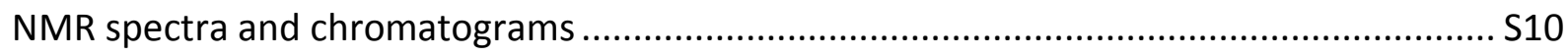

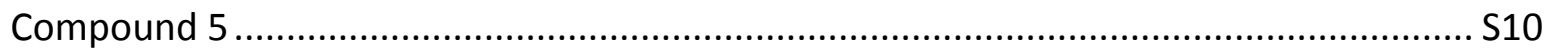

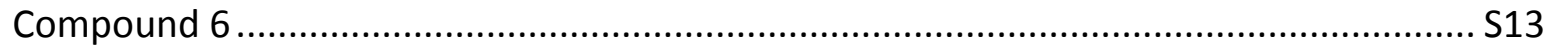

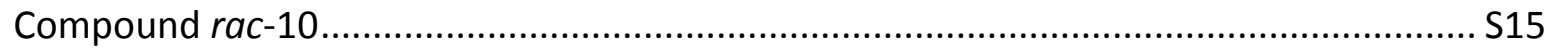

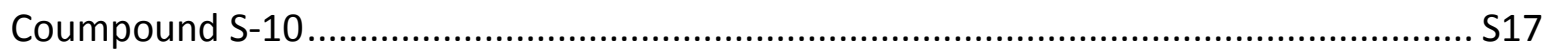

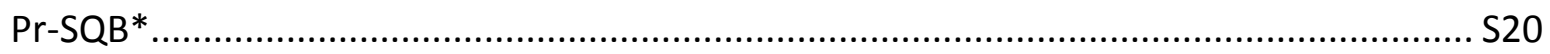

Pr-SQA

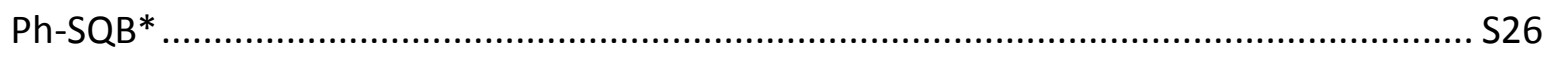

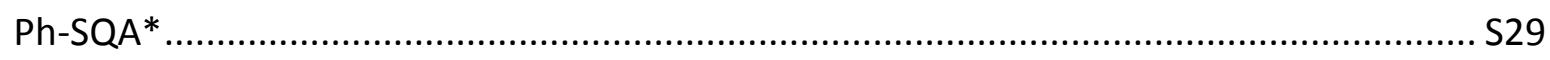

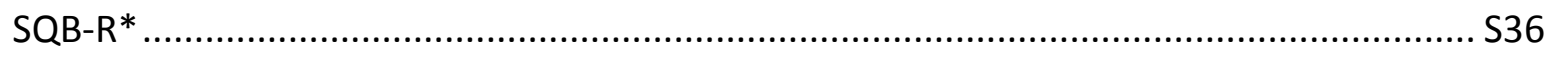

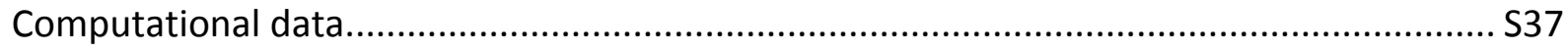




\section{Synthesis}

Calculation of the formation probabilities of the stereoisomers of the chiral squaraines

In a statistical distribution, the probability of the formation of a particular stereoisomer $P$ can be calculated from the composition of the starting material $p R$ and $p S$ using the following equations:

$$
\begin{gathered}
P(R S)=2 \times p R \times p S \\
P(S S)=p S^{2} \\
P(R R)=p R^{2}
\end{gathered}
$$

Table S1 summarizes the calculated formation probabilities for the respective stereoisomers of all the discussed C(3)-chiral squaraines:

Table S1. Composition of starting material and calculated formation probabilities for the possible stereoisomers for Pr-SQB*, Ph-SQB*, Pr-SQA*, and Ph-SQA*

\begin{tabular}{cccccc}
\hline & pR & pS & P(RR) & P(SS) & P(RS) \\
\hline Pr-SQB* & 0.014 & 0.986 & 0.0002 & 0.972 & 0.028 \\
\hline Ph-SQB* & 0.026 & 0.974 & 0.0007 & 0.949 & 0.051 \\
\hline Pr-SQA* & 0.008 & 0.992 & 0.00006 & 0.984 & 0.016 \\
\hline Ph-SQA* & 0.008 & 0.992 & 0.00006 & 0.984 & 0.016 \\
\hline
\end{tabular}

Calculation of the selectivity factor of the kinetic resolution

This quantity can be calculated in terms of conversion $c$ and enantiomeric excess ee using the following equation ${ }^{1}$ :

$$
S=\frac{k_{\mathrm{fast}}}{k_{\mathrm{slow}}}=\frac{\ln [(1-c)(1-e e)]}{\ln [(1-c)(1+e e)]}
$$


Table S2 summarizes the achieved conversion, enantiomeric excess and selectivity factor of various resolutions of the indolenine 10 :

Table S2. Conversion, enantiomeric excess and calculated selectivity factors of the kinetic resolution of 9 by asymmetric hydrogenation

\begin{tabular}{cccc}
\hline batch & conversion & enantiomeric excess & selectivity factor $\boldsymbol{S}$ \\
\hline $\mathbf{1}$ & $64 \%$ & $79 \%$ & 5.86 \\
\hline $\mathbf{2}$ & $82 \%$ & $97 \%$ & 5.20 \\
\hline $\mathbf{3}$ & $81 \%$ & $98 \%$ & 5.82 \\
\hline
\end{tabular}

\section{X-ray crystallography}

X-ray diffraction data were collected at $100 \mathrm{~K}$ on a Bruker D8 Quest Kappa Diffractometer with a Photon100 CMOS or CPAD Photonll detector and multi-layered mirror monochromated CuK $\alpha$ radiation. The structure was solved using direct methods, expanded with Fourier techniques and refined with the Shelx software package. ${ }^{2}$ All non-hydrogen atoms were refined anisotropically. Hydrogen atoms were included in the structure factor calculation on geometrically idealized positions. Plots were done using the software package OLEX2. ${ }^{3}$

For Ph-SQB*, single crystals were obtained by layering a DCM solution with $n$-hexane followed by slow evaporation. For Pr-SQB*, single crystals were obtained by crystallization form $\mathrm{DCM} / n$-hexane at $4{ }^{\circ} \mathrm{C}$. 
Table S3. Bond lengths of the polymethine chains of the discussed SQB-type squaraines

\begin{tabular}{|l|l|l|l|l|l|l|l|l|}
\hline & $\begin{array}{l}\text { N1-C1/ } \\
\AA\end{array}$ & $\begin{array}{l}\text { C1-C2/ } \\
\AA\end{array}$ & $\begin{array}{l}\text { C2-C3/ } \\
\AA\end{array}$ & $\begin{array}{l}\text { C3-C4/ } \\
\AA\end{array}$ & $\begin{array}{l}\text { C4-C5/ } \\
\AA\end{array}$ & $\begin{array}{l}\text { C5-C6/ } \\
\AA\end{array}$ & $\begin{array}{l}\text { C6-C7/ } \\
\AA\end{array}$ & $\begin{array}{l}\text { C7-N2/ } \\
\AA\end{array}$ \\
\hline SQB $^{4}$ & 1.351 & 1.389 & 1.386 & 1.439 & 1.433 & 1.399 & 1.379 & 1.360 \\
\hline Pr-SQB* & 1.367 & 1.383 & 1.404 & 1.439 & 1.453 & 1.383 & 1.405 & 1.348 \\
\hline $\begin{array}{l}\text { Ph-SQB* } \\
\text { Crystal }\end{array}$ & 1.353 & 1.392 & 1.385 & 1.439 & 1.437 & 1.394 & 1.375 & 1.362 \\
\hline $\begin{array}{l}\text { Ph-SQB* } \\
\text { Calcd }\end{array}$ & 1.370 & 1.388 & 1.400 & 1.451 & 1.451 & 1.400 & 1.388 & 1.370 \\
\hline $\begin{array}{l}\text { TPh-SQB } \\
5\end{array}$ & 1.303 & 1.429 & 1.365 & 1.435 & 1.424 & 1.396 & 1.395 & 1.339 \\
\hline
\end{tabular}



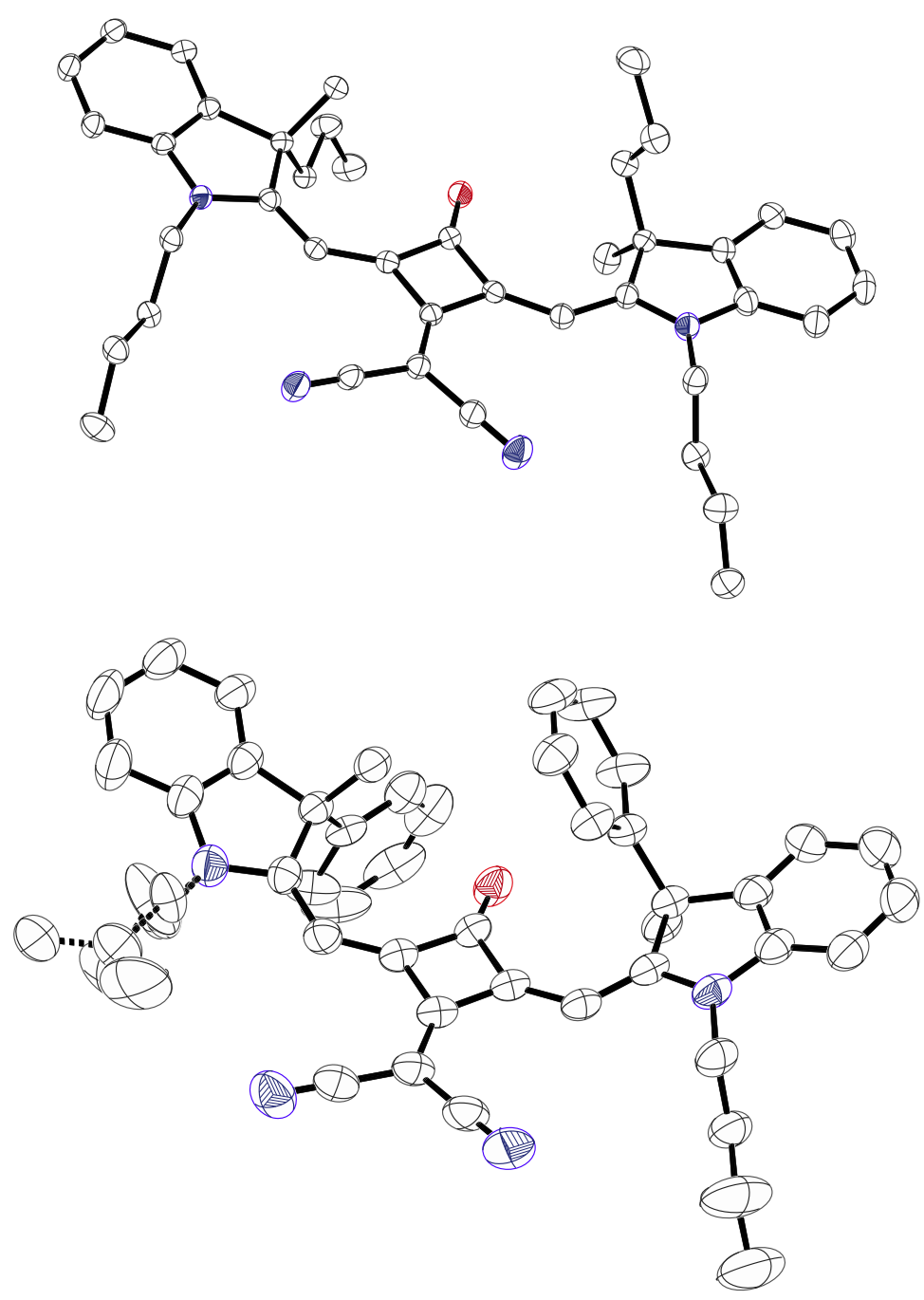

Figure S1. ORTEP plots of the crystal structures of Pr-SQB* (top) and Ph-SQB* (bottom). Thermal ellipsoids are at 50\% probability level. Dashed bonds indicate disorder.

Crystal data for Pr-SQB* $\left(\mathrm{C}_{41} \mathrm{H}_{48} \mathrm{~N}_{4} \mathrm{O}\right): \mathrm{Mr}=612.83,0.239 \times 0.182 \times 0.094 \mathrm{~mm}^{3}$, monoclinic space group P21, $\mathrm{a}=12.5152(11) \AA, \alpha=90^{\circ}, \mathrm{b}=8.1909(7) \AA, \beta=109.467(2)^{\circ}, \mathrm{c}=$ 18.3478(16) $\AA, \gamma=90^{\circ}, V=1773.3(3) \AA^{3}, Z=2, \rho($ calcd $)=1.148 \mathrm{~g} \cdot \mathrm{cm}^{-3}, \mu=0.532 \mathrm{~mm}^{-1}$, $\mathrm{F}(000)=660.0, \operatorname{GooF}\left(\mathrm{F}^{2}\right)=1.030$, Flack $=0.00(5), \mathrm{R} 1=0.0392, \mathrm{wR} 2=0.1034$ for $\mathrm{I}>2$ sigma $(\mathrm{I})$, $R 1=0.0397, w R 2=0.1041$ for all data, 6912 unique reflections $\left[\theta=67.679^{\circ}\right]$ with $a$ completeness of $99.9 \%$ and 421 parameters, 1 restraint.

Crystal data for Ph-SQB* $\left(\mathrm{C}_{47} \mathrm{H}_{44} \mathrm{~N}_{4} \mathrm{O}\right): \mathrm{Mr}=680.86,0.368 \times 0.250 \times 0.101 \mathrm{~mm}^{3}$, monoclinic space group P21, $a=9.5514(13) \AA, \alpha=90^{\circ}, b=10.8418(15) \AA, \beta=102.372(5)^{\circ}, c=$ 18.966(3) $\AA, \gamma=90^{\circ}, V=1918.4(5) \AA^{3}, Z=2, \rho($ calcd $)=1.179 \mathrm{~g} \cdot \mathrm{cm}^{-3}, \mu=0.547 \mathrm{~mm}^{-1}, F(000)=$ 724.0, GooF $\left(F^{2}\right)=1.042$, Flack $=0.05(5), R 1=0.0368$, wR2 $=0.1009$ for $I>2$ sigma(I), R1= $0.0377, w R 2=0.1019$ for all data, 7542 unique reflections $\left[\theta=67.679^{\circ}\right]$ with a completeness of $100.0 \%$ and 506 parameters, 5 restraints. 


\section{UV-vis spectra}
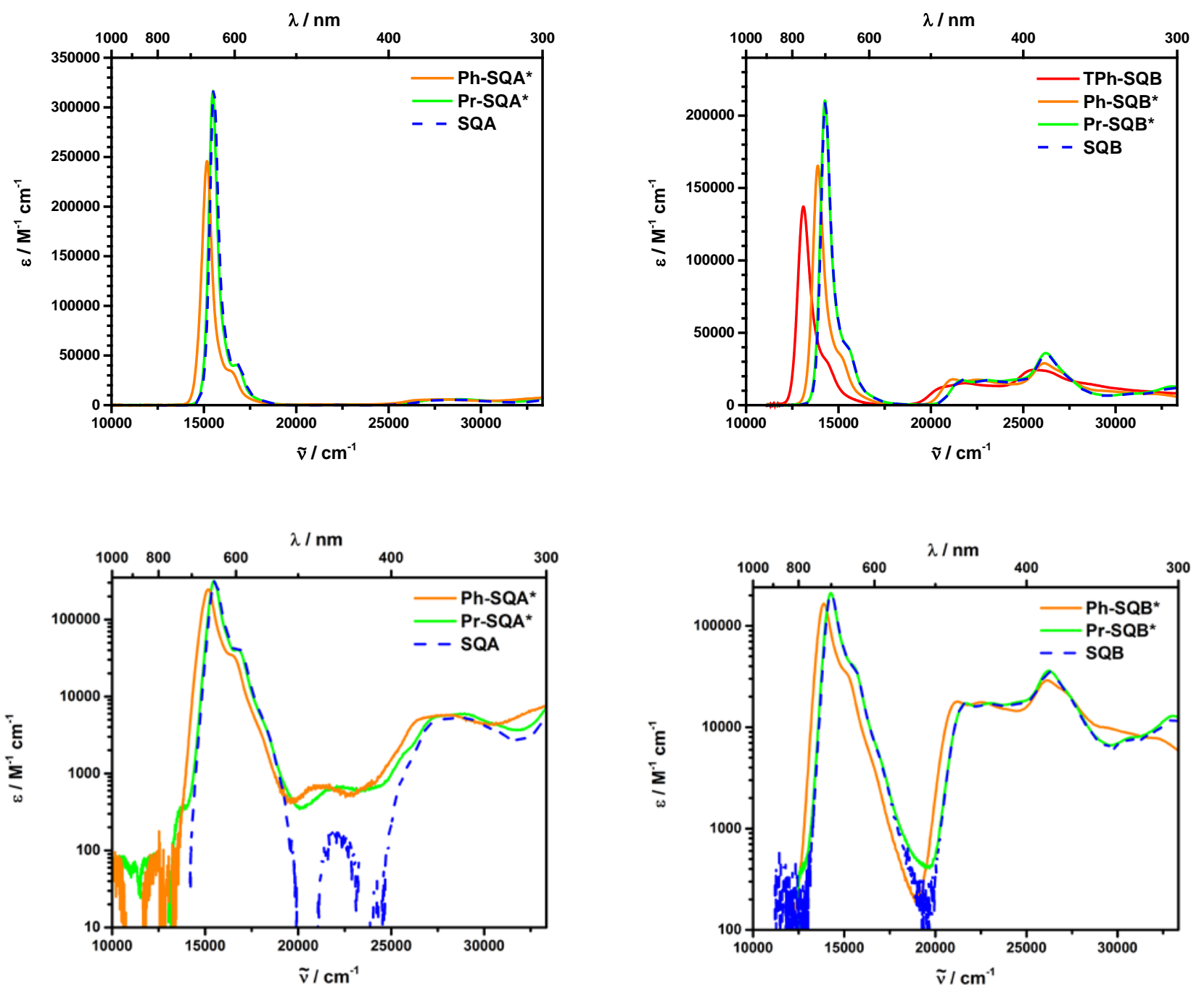

Figure S2. Full range (1000-300 nm) plots of the UV-vis spectra of the SQA- (left) and SQB-type squaraines (right) in toluene. Top: linear scale, bottom: logarithmic scale.

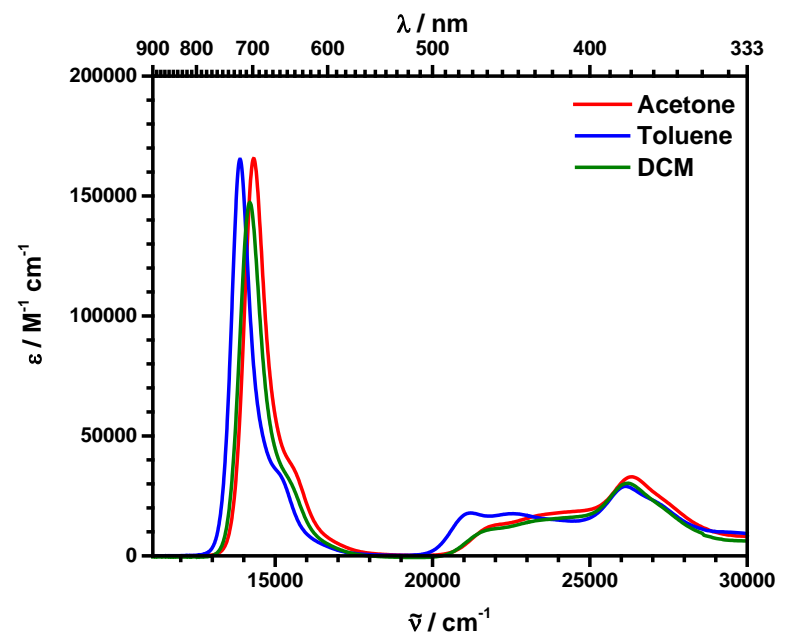

Figure S3. Absorption spectra of Ph-SQB* in various solvents. 


\section{ECD spectra}
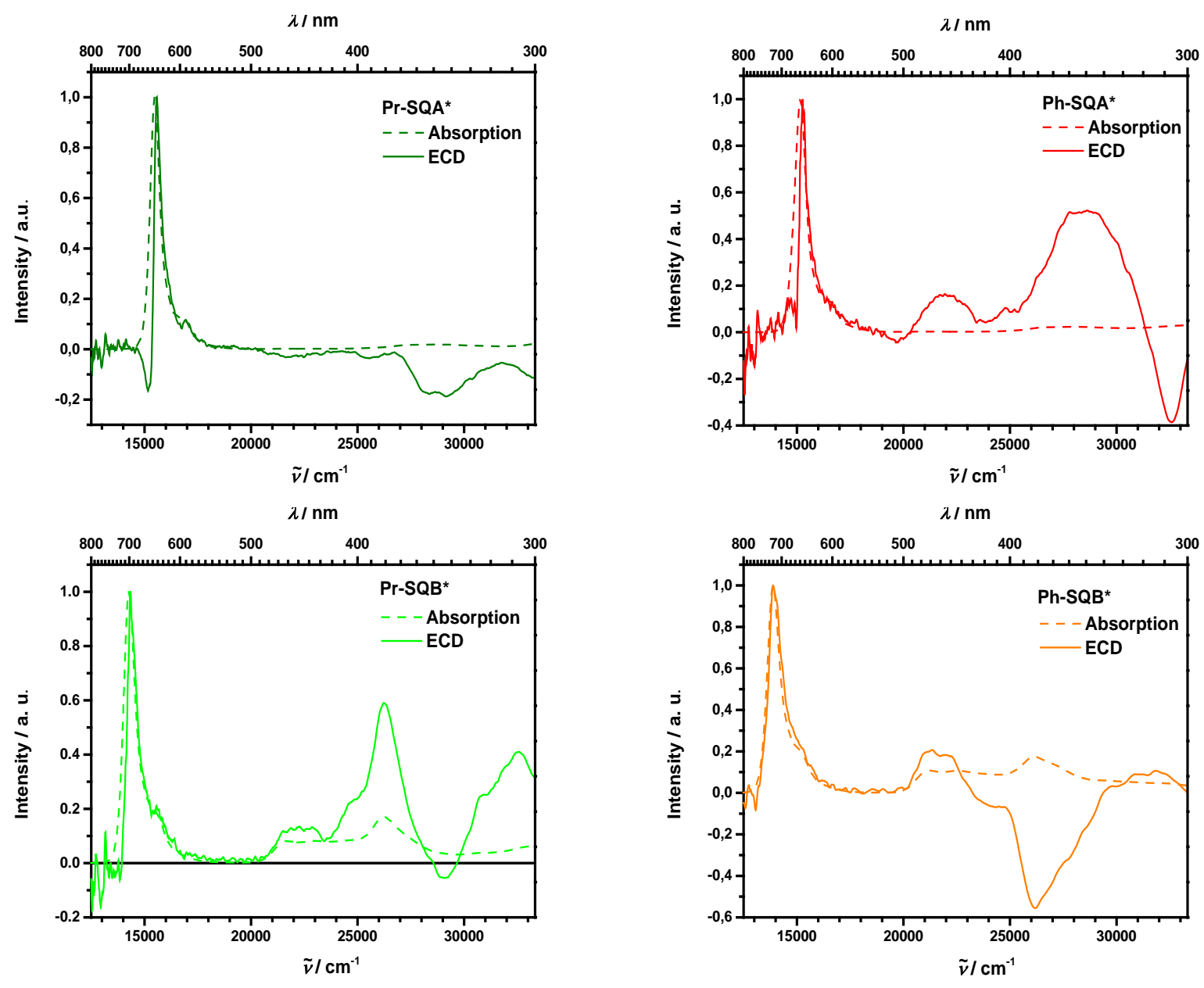

Figure S4. Normalized absorption and ECD spectra in toluene. Top: SQA-type squaraines, bottom: SQB-type squaraines; left: propyl-substituted derivatives, right: phenyl-substituted derivatives.

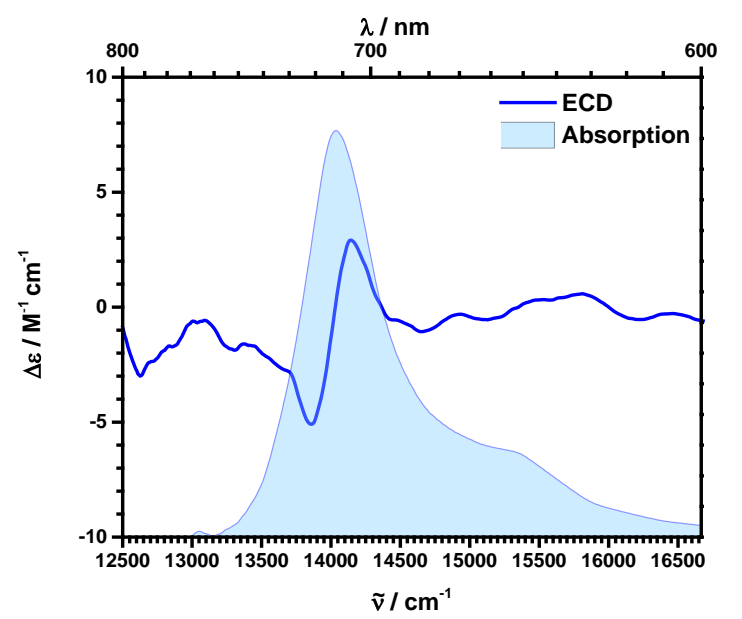

Figure S5. Overlay of the ECD and absorption spectrum of SQB-R* in toluene. 


\section{Calculation of transition moments and rotatory strengths}

The following equations were used to calculate the transition moment $\mu_{\mathrm{eg}}^{26}$ and rotatory strength $R^{7}$ :

$$
\begin{gathered}
\mu_{\mathrm{eg}}^{2}=\frac{3 h c \varepsilon_{0}}{2000 \pi^{2}} \frac{\ln (10)}{N_{\mathrm{A}}} \frac{9 n}{\left(n^{2}+2\right)^{2}} \int \frac{\varepsilon(\tilde{v})}{\widetilde{v}} \mathrm{~d} \tilde{v} \\
R=\frac{3(2303) \hbar c}{16 \pi^{2} N_{\mathrm{A}}} \int \frac{\Delta \varepsilon(\tilde{v})}{\tilde{v}} \mathrm{~d} \widetilde{v}
\end{gathered}
$$

Where $h$ is Planck's constant, $\hbar$ is the reduced Planck's constant, $c$ is the speed of light in vacuum, $\varepsilon_{0}$ is the vacuum permittivity, $N_{\mathrm{A}}$ is Avogadro's constant, $n$ is the refractive index of the solvent, $\tilde{v}$ is the wavenumber, $\varepsilon(\tilde{v})$ is the absorption coefficient dependent on the wavenumber (absorption spectrum) and $\varepsilon(\tilde{v})$ the difference of the absorption coefficient of left and right circularly polarized light dependent on the wavenumber (ECD spectrum). 


\section{NMR spectra, HRMS spectra and chromatograms}

\section{Compound 5}
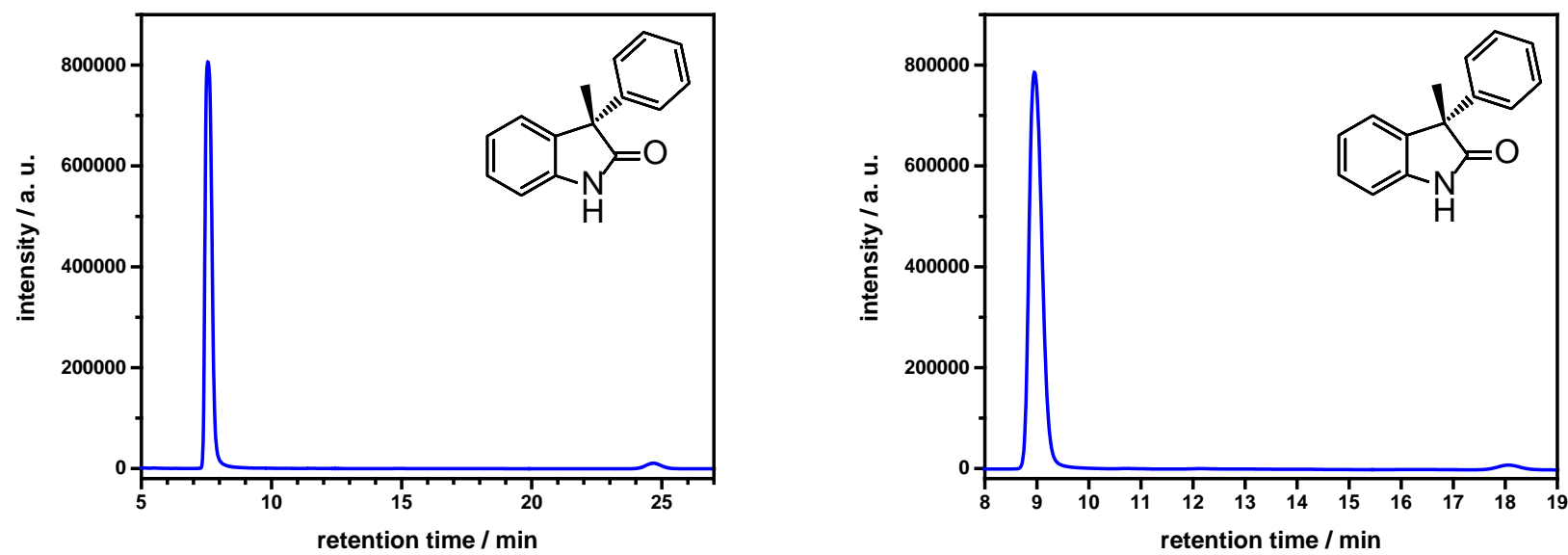

Figure S6. Chromatograms for batch 1 (left) and batch 2 (right) of compound $\boldsymbol{S}$-5.

Table S4. Data obtained from analytical HPLC of compound 5

LUX Cellulose-2 (batch 1), LUX Cellulose-4 (batch 2); Hexane/iPrOH 9:1; $1 \mathrm{~mL} / \mathrm{min}$; detection at $254 \mathrm{~nm} ; t(1)=7.6 \mathrm{~min}$ (Cellulose-2), $9.0 \mathrm{~min}$ (Cellulose-4); $t(2)=7.6 \mathrm{~min}$ (Cellulose-2), 24.7 min (Cellulose-4)

\begin{tabular}{|c|c|c|c|c|c|}
\hline & Area 1 & Area 2 & $\% 1$ & $\% 2$ & \%ee \\
\hline $\begin{array}{c}\text { Batch 1 (left, } \\
\text { for Ph-SQB*) }\end{array}$ & 248083 & 6665 & 97.4 & 2.6 & 94.8 \\
\hline $\begin{array}{c}\text { Batch 2 } \\
\text { (right, for } \\
\text { Ph-SQA*) }\end{array}$ & 225608 & 1873 & 99.2 & 0.8 & 98.4 \\
\hline
\end{tabular}




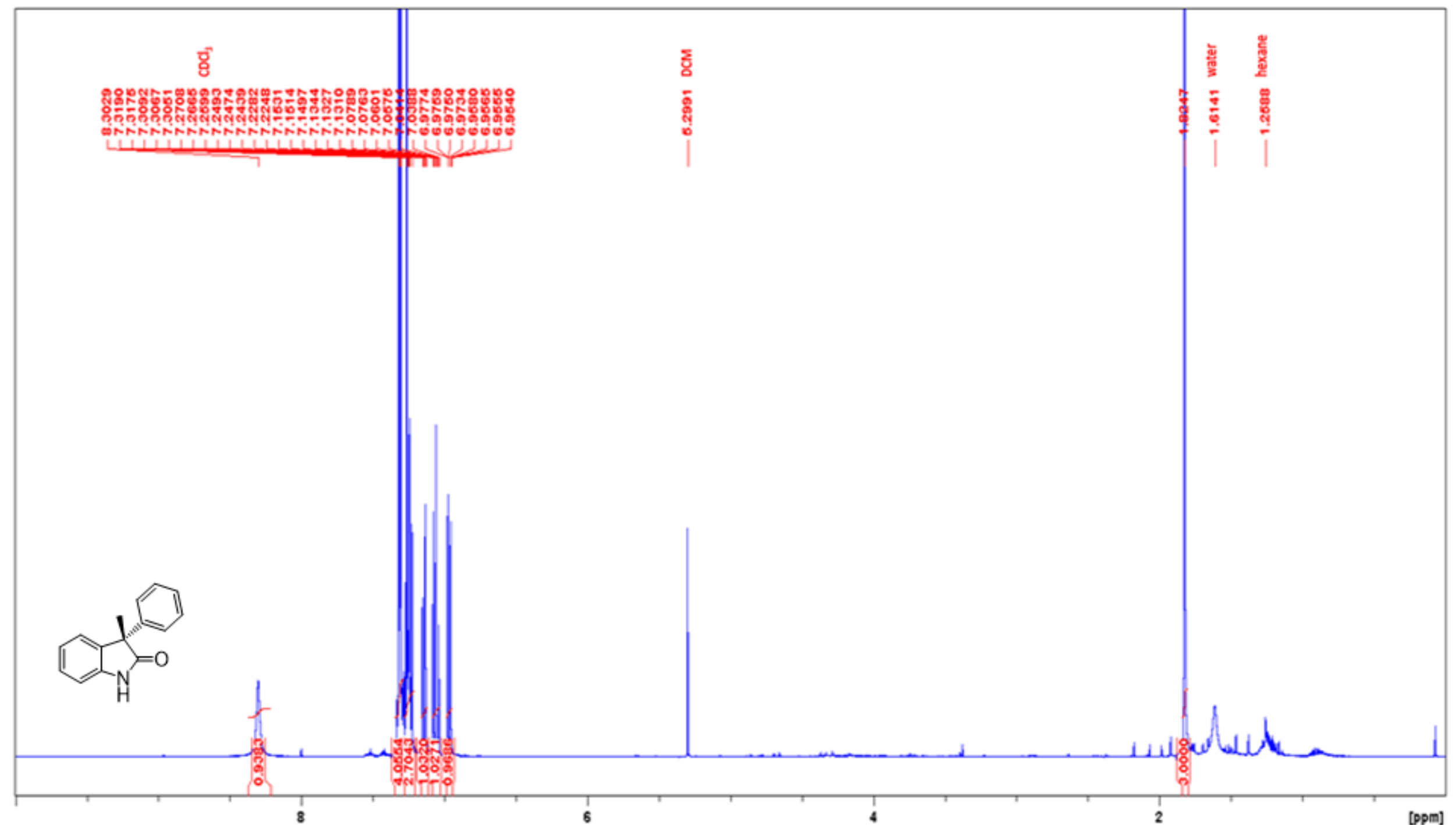

Figure S7. ${ }^{1} \mathrm{H}$ NMR spectrum $\left(400 \mathrm{MHz}, \mathrm{CDCl}_{3}\right)$ of compound $\mathbf{5}$, batch 1 . 


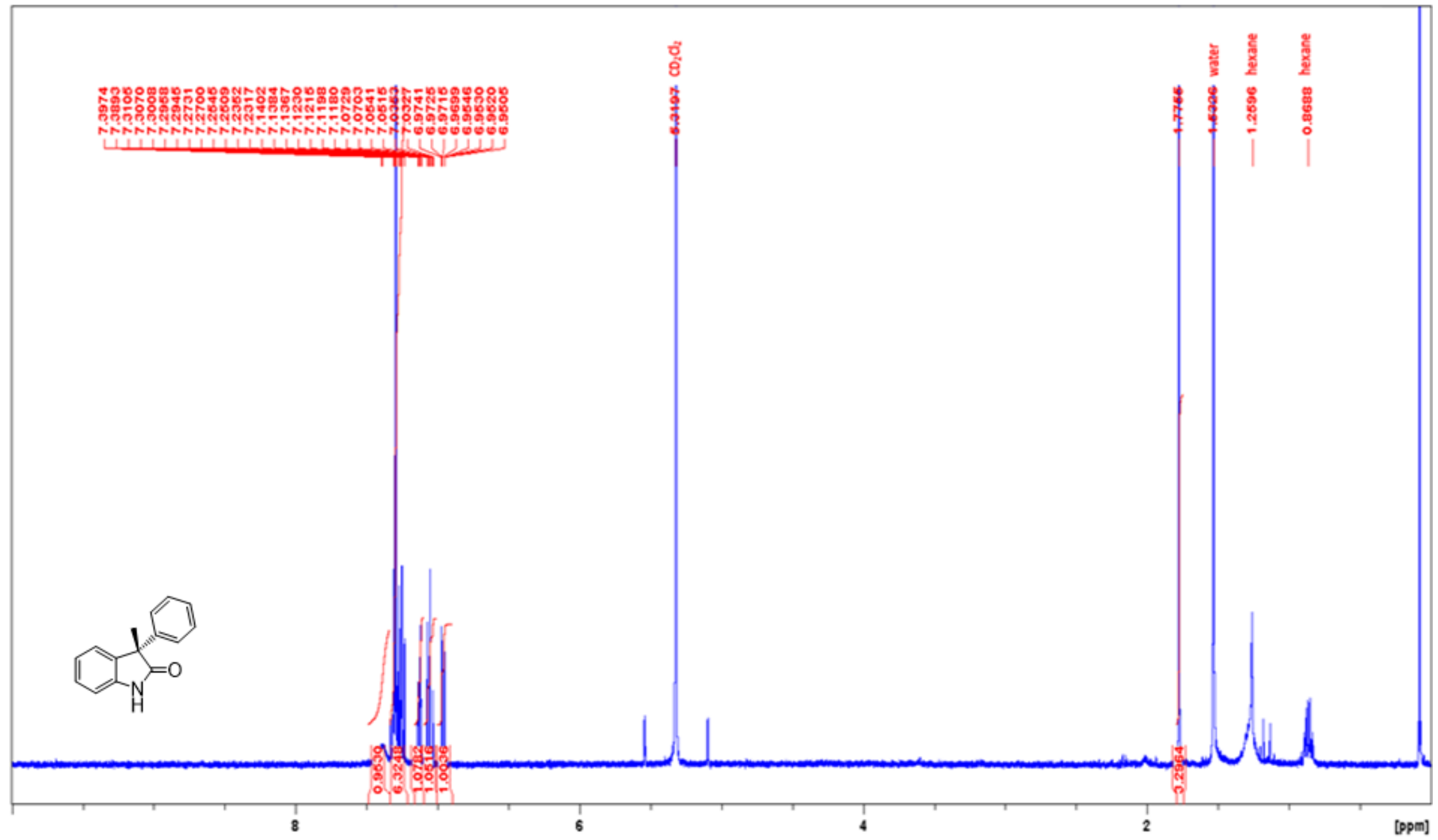

Figure S8. ${ }^{1} \mathrm{H}$ NMR spectrum $\left(400 \mathrm{MHz}, \mathrm{CD}_{2} \mathrm{Cl}_{2}\right)$ of compound 5 , batch 2 . 


\section{Compound 6}

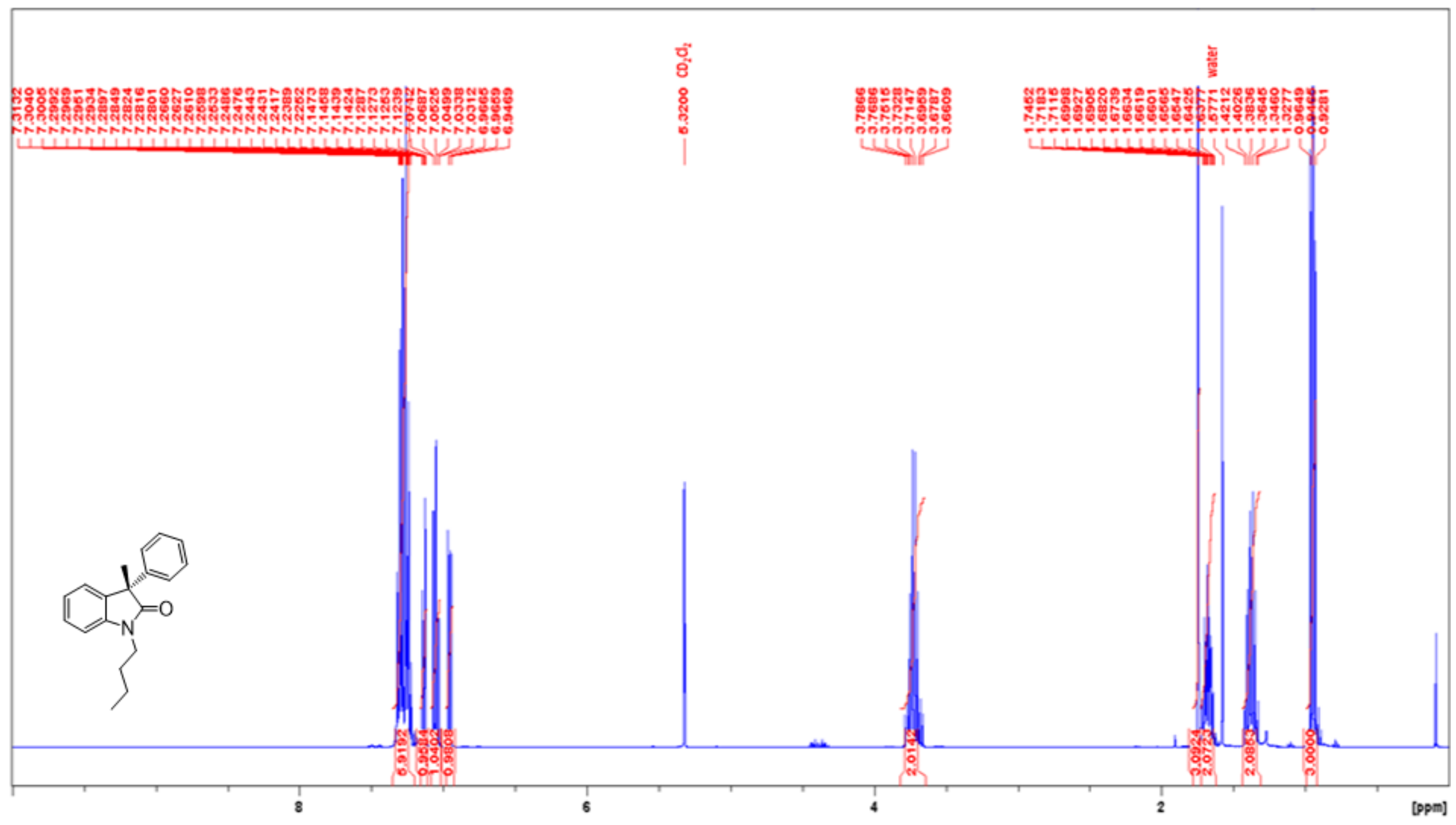

Figure S9. ${ }^{1} \mathrm{H}$ NMR spectrum (400 MHz, $\mathrm{CD}_{2} \mathrm{Cl}_{2}$ ) of compound 6 . 


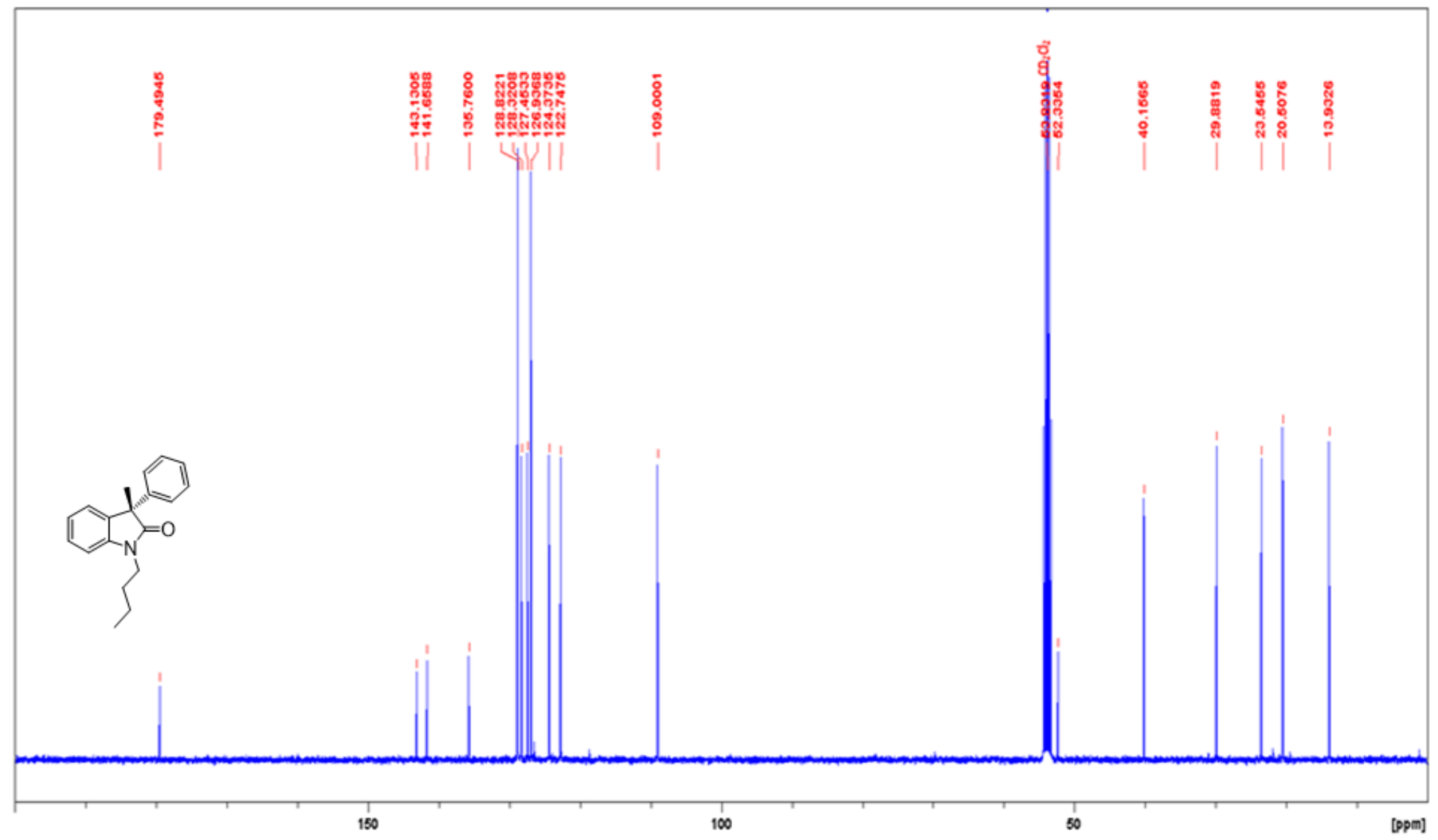

Figure S10. ${ }^{13} \mathrm{C}\left\{{ }^{1} \mathrm{H}\right\}$ NMR spectrum (100 $\mathrm{MHz}, \mathrm{CD}_{2} \mathrm{Cl}_{2}$ ) of compound 6 . 


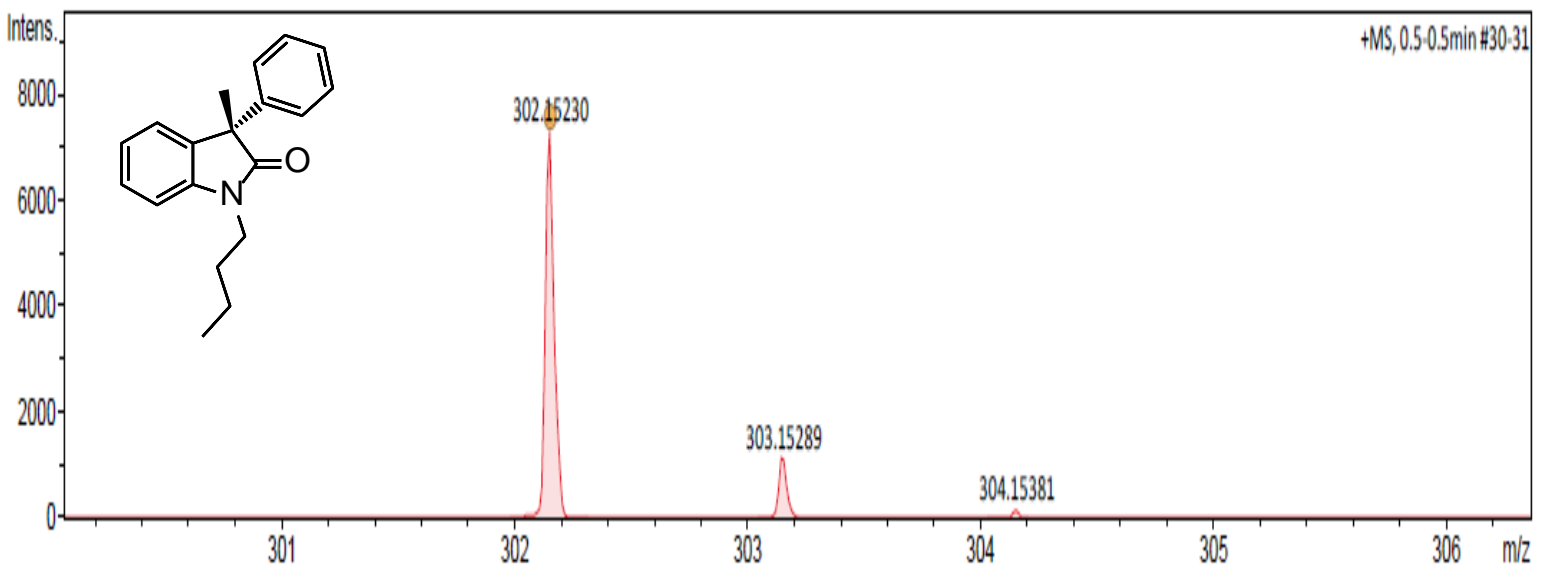

Figure S11. HRMS (ESI) spectrum of compound 6.

\section{Compound rac-10}

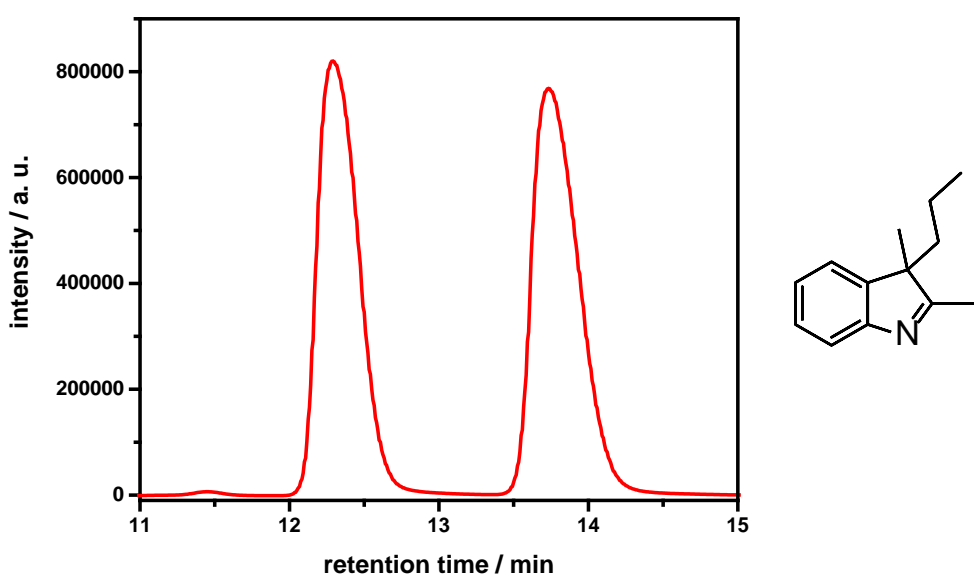

Figure S12. Chromatogram of rac-10 (LUX Cellulose-4; Hexane/i-PrOH 99:1; $1 \mathrm{~mL} / \mathrm{min}$; detection at $254 \mathrm{~nm}$ ). 


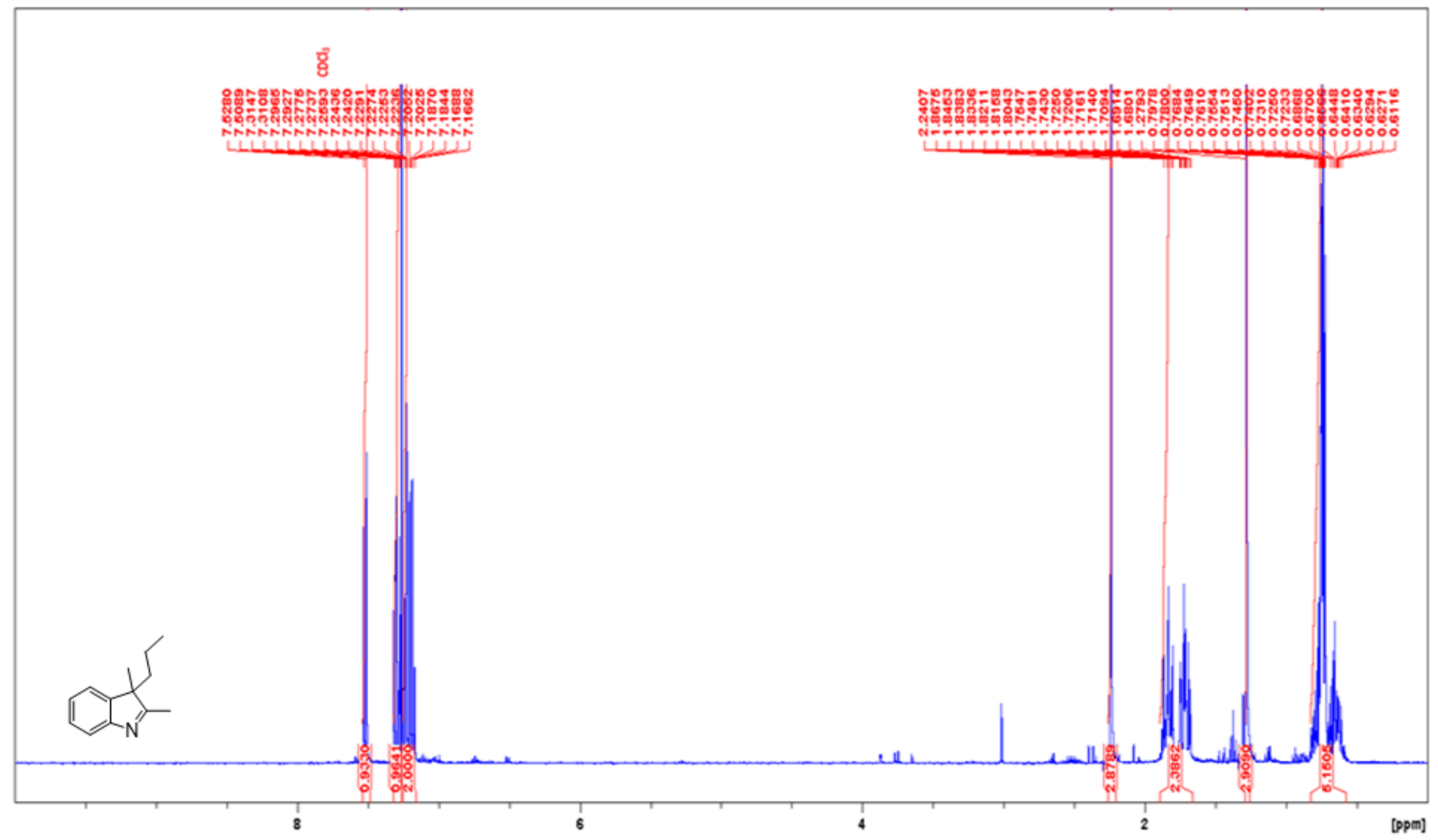

Figure S13. ${ }^{1} \mathrm{H} \mathrm{NMR}\left(400 \mathrm{MHz}, \mathrm{CDCl}_{3}\right)$ spectrum of compound rac-10. 
Coumpound S-10
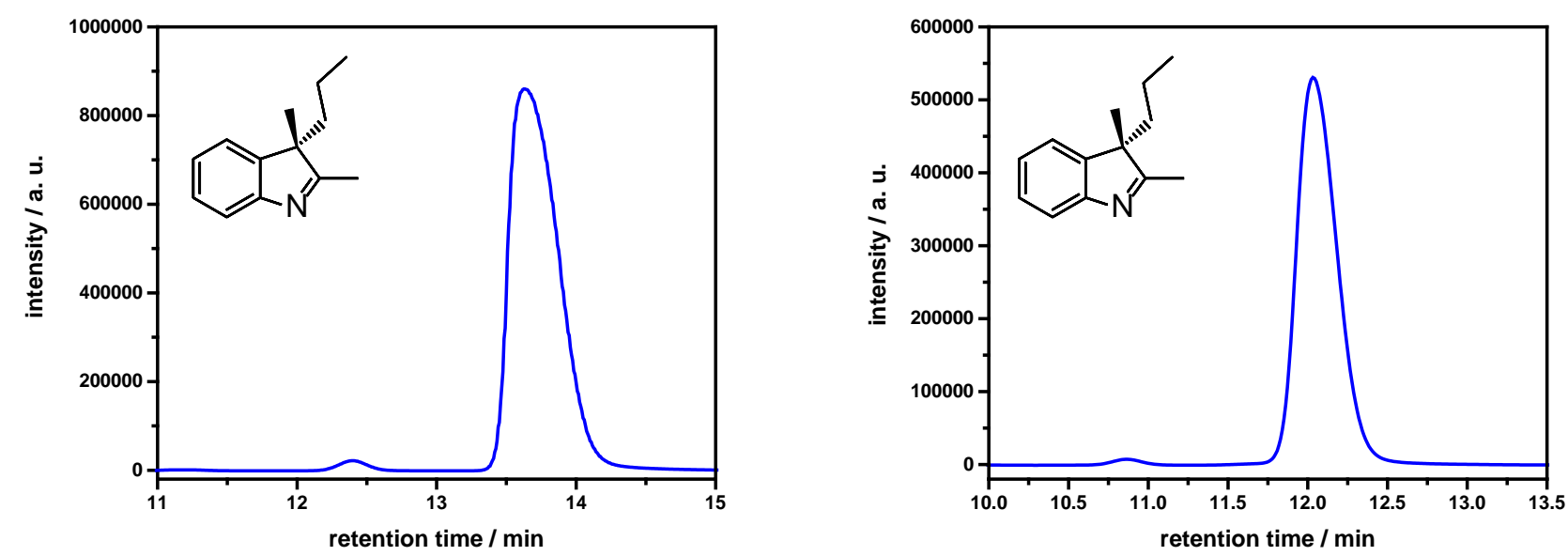

Figure S14. Chromatograms for batch 2 (left) and batch 3 (right) of compound $\mathbf{S}-\mathbf{1 0}$.

Table S5. Data obtained from analytical HPLC of compound S-10

LUX Cellulose-2 (batch 3), LUX Cellulose-4 (batch 2); Hexane/i-PrOH 99:1; $1 \mathrm{~mL} / \mathrm{min}$; detection at $254 \mathrm{~nm} ; t(1)=10.4 \mathrm{~min}$ (Cellulose-2), $12.4 \mathrm{~min}$ (Cellulose-4); $t(2)=12.0 \mathrm{~min}$ (Cellulose-2), $13.6 \mathrm{~min}$ (Cellulose-4)

\begin{tabular}{|c|c|c|c|c|c|}
\hline & Area 1 & Area 2 & $\% 1$ & $\% 2$ & \%ee \\
\hline $\begin{array}{c}\text { Batch 2 (left, } \\
\text { for Pr-SQB*) }\end{array}$ & 4911 & 350382 & 1.4 & 98.6 & 97.2 \\
\hline $\begin{array}{c}\text { Batch 3 } \\
\text { (right, for } \\
\text { Pr-SQA*) }\end{array}$ & 1310 & 155730 & 0.8 & 99.2 & 98.4 \\
\hline
\end{tabular}




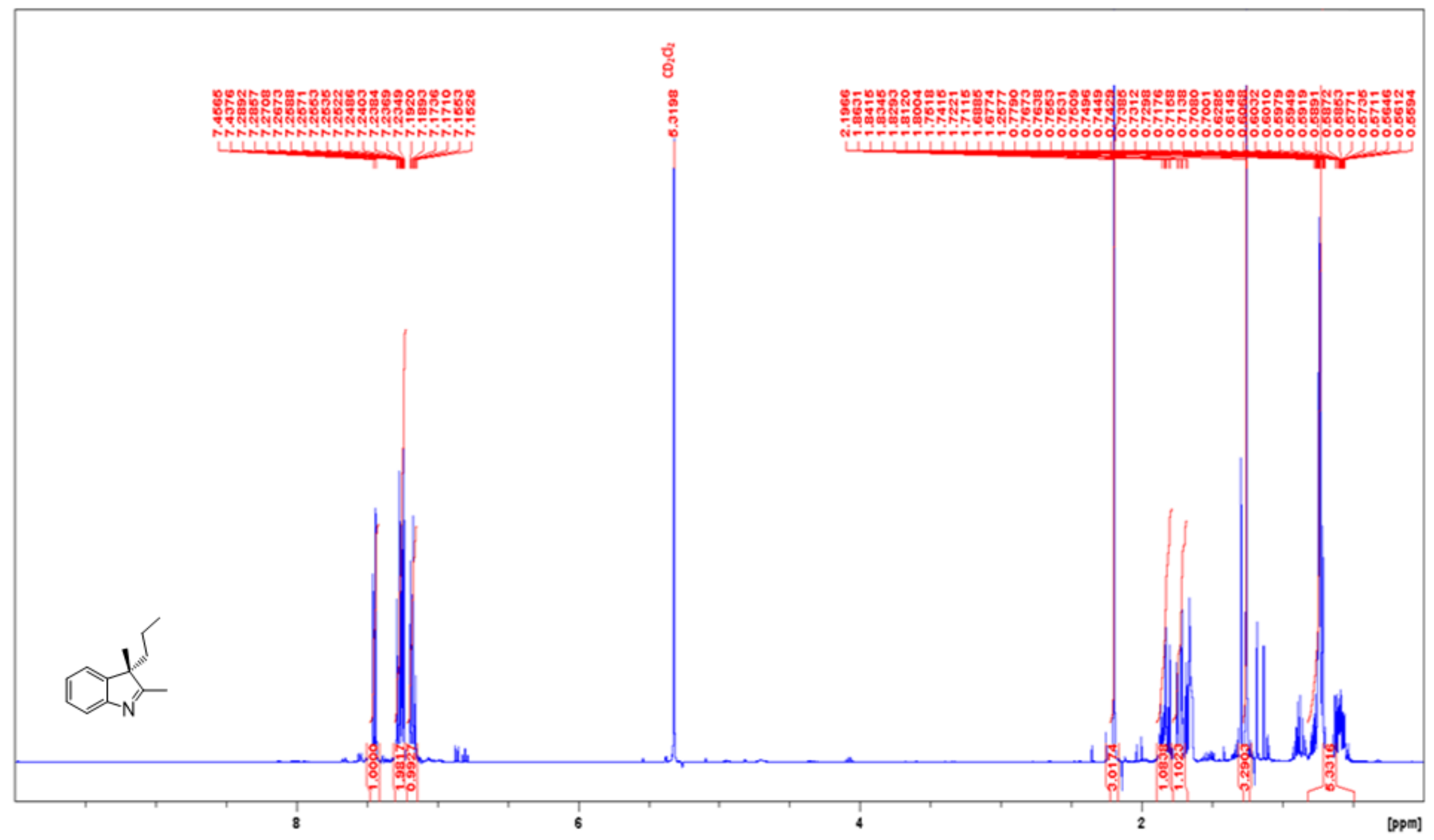

Figure S15. ${ }^{1} \mathrm{H}$ NMR $\left(400 \mathrm{MHz}, \mathrm{CD}_{2} \mathrm{Cl}_{2}\right.$ ) spectrum of compound $\boldsymbol{S}$-10, batch 2 . 


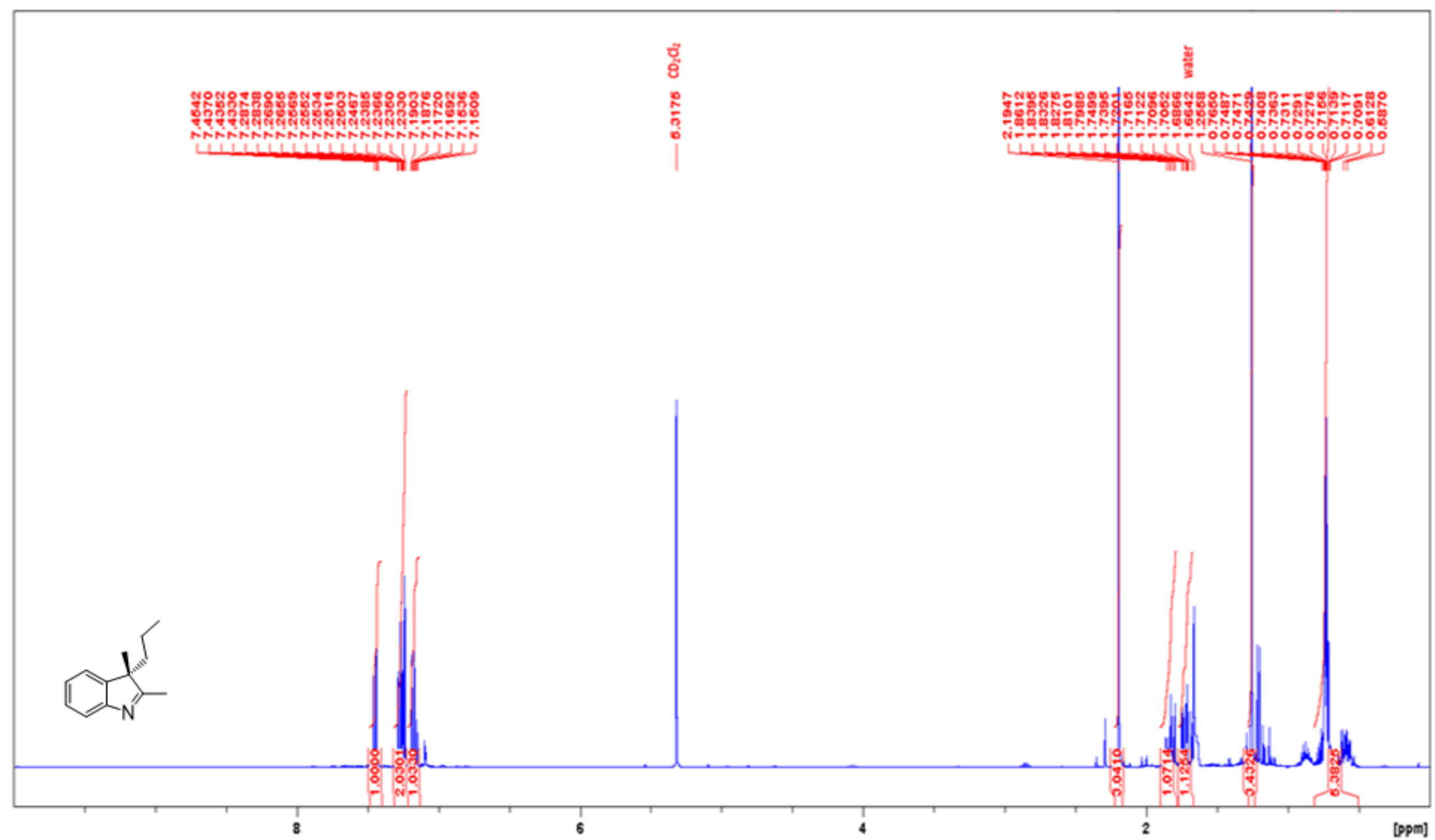

Figure S16. ${ }^{1} \mathrm{H}-\mathrm{NMR}\left(400 \mathrm{MHz}, \mathrm{CD}_{2} \mathrm{Cl}_{2}\right)$ spectrum of compound $\boldsymbol{S}$-10, batch 3 . 

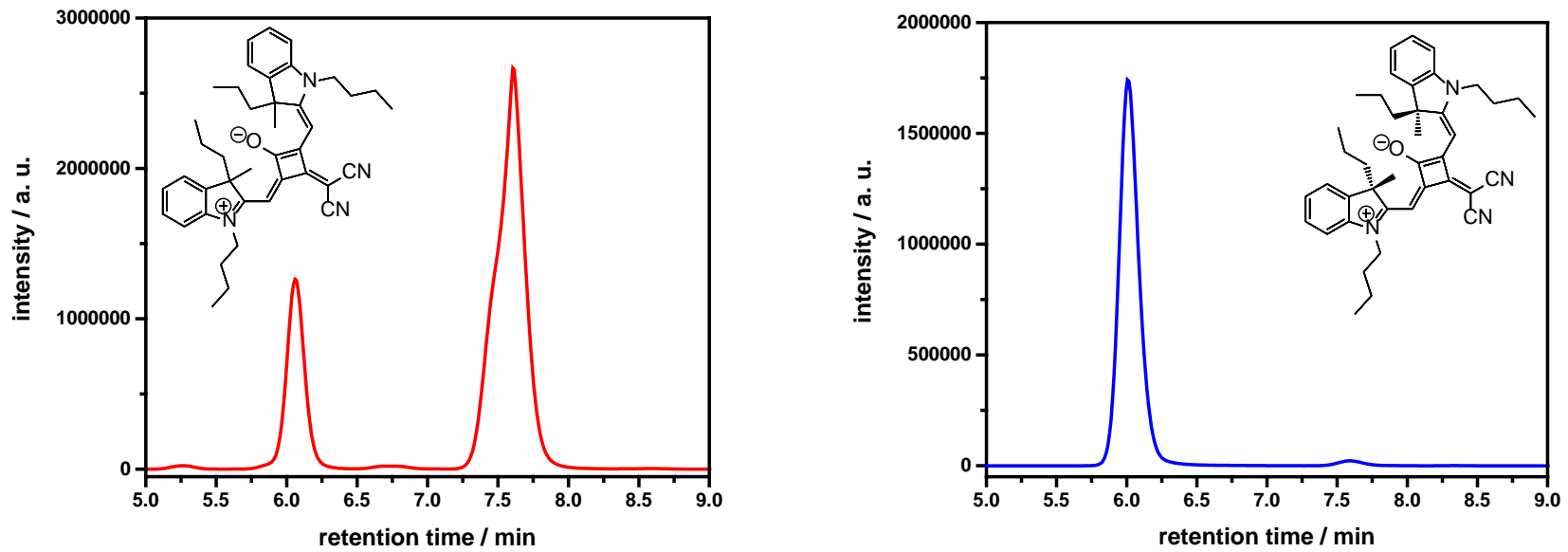

Figure S17. Chromatograms of Pr-SQB*. Left: mixture of stereoisomers, right: SS-Pr-SQB*.

Table S6. Data obtained from analytical HPLC of Pr-SQB*.

\begin{tabular}{|c|c|c|c|c|}
\hline \multicolumn{5}{|c|}{ LUX i-Amylose-3, Hexane/DCM/i-PrOH 95:27:3, $1 \mathrm{~mL} / \mathrm{min}$, detection at $700 \mathrm{~nm}$; } \\
\hline & Area 1 & Area 2 & $\% 1$ & $\% 2$ \\
\hline $\begin{array}{c}\text { Pr-SQB* } \\
\text { mixture (SS, RR, } \\
\text { RS), left }\end{array}$ & 193480 & 627326 & 23.6 & 76.4 \\
\hline $\begin{array}{c}\text { SS-Pr-SQB*, } \\
\text { right }\end{array}$ & 288199 & 4495 & 98.5 & 1.5 \\
\hline
\end{tabular}

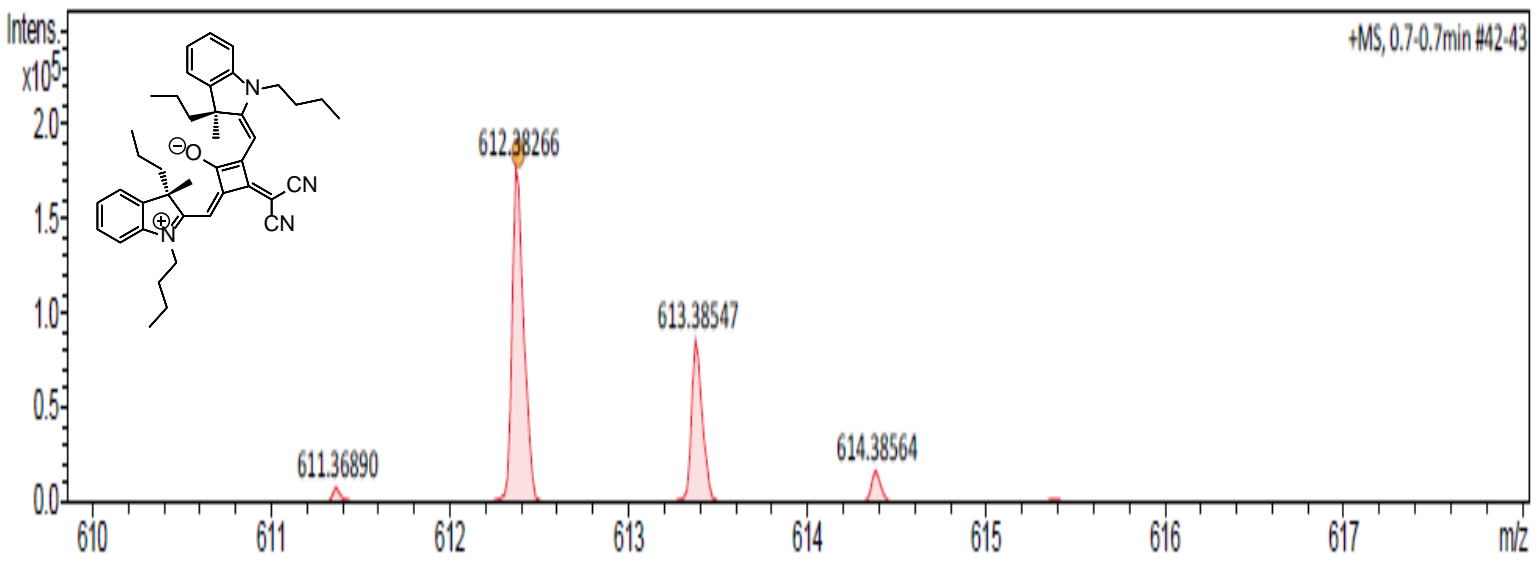

Figure S18. HRMS (ESI) spectrum of Pr-SQB*. 


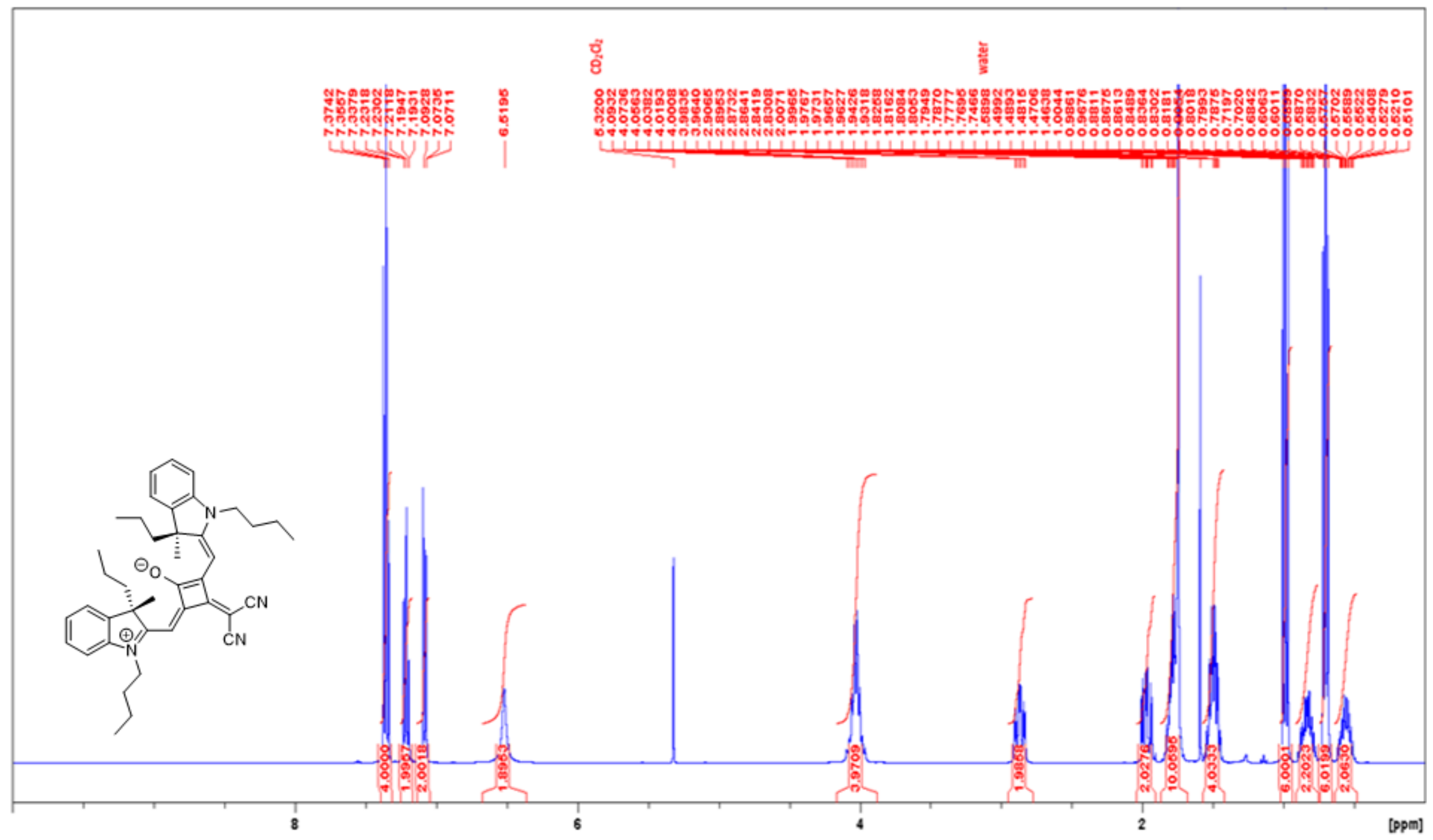

Figure S19. ${ }^{1} \mathrm{H}$ NMR spectrum $\left(400 \mathrm{MHz}, \mathrm{CD}_{2} \mathrm{Cl}_{2}\right)$ of Pr-SQB* 


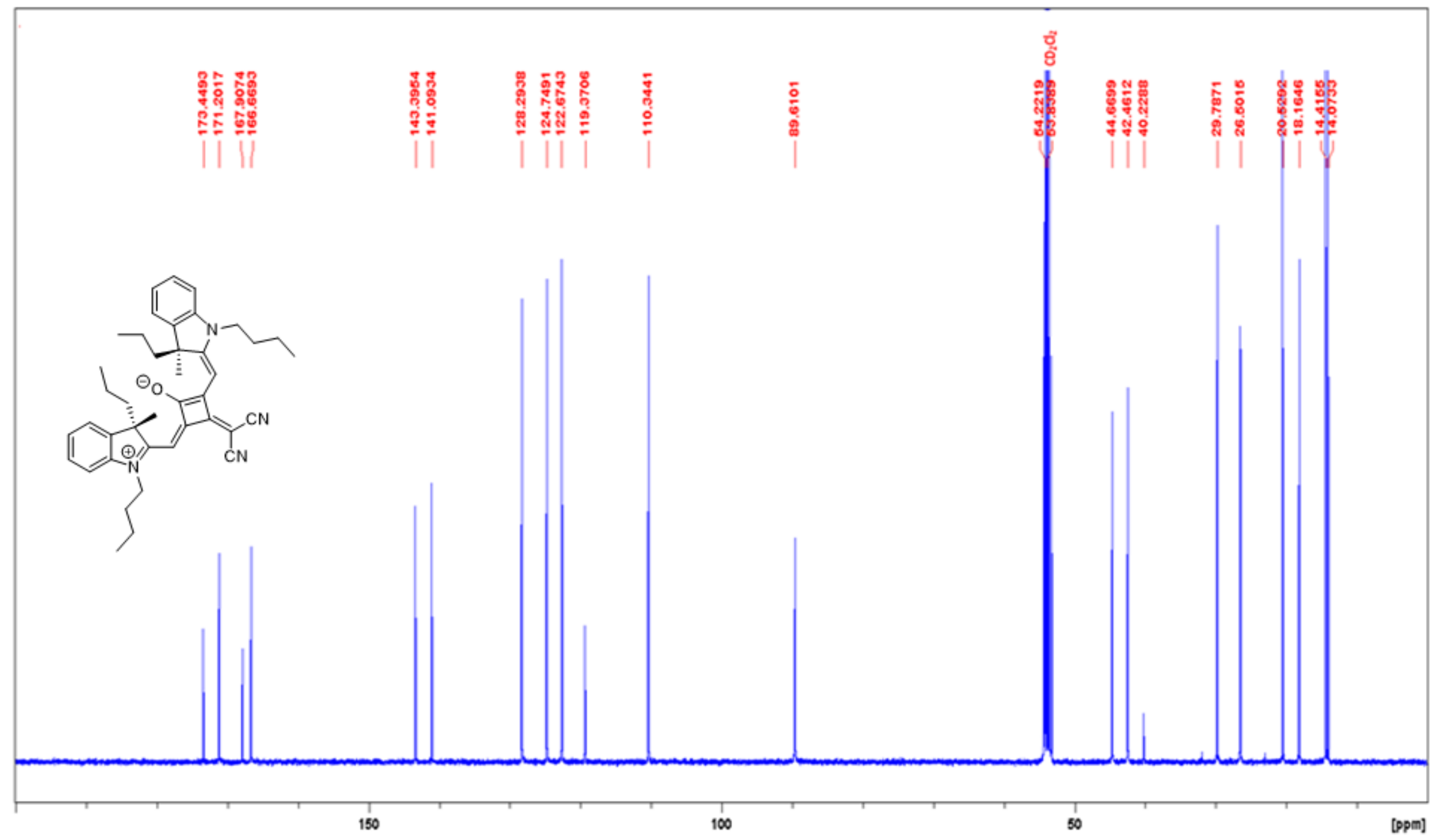

Figure S20. $\left.{ }^{13} \mathrm{C}^{1}{ }^{1} \mathrm{H}\right\} \mathrm{NMR}$ spectrum $\left(100 \mathrm{MHz}, \mathrm{CD}_{2} \mathrm{Cl}_{2}\right)$ of Pr-SQB*. 


\section{Pr-SQA*}
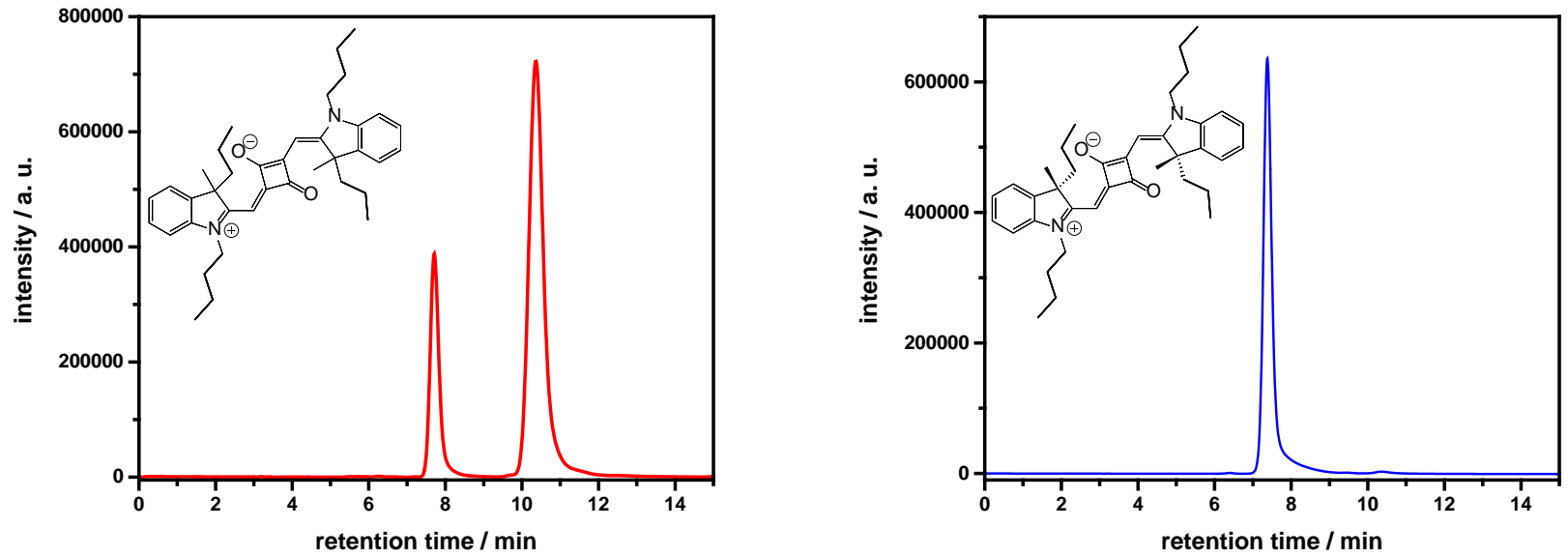

Figure S21. Chromatograms of Pr-SQA*. Left: mixture of stereoisomers, right: SS-Pr-SQA*.

Table S7. Data obtained from analytical HPLC of Pr-SQA*.

\begin{tabular}{|c|c|c|c|c|}
\hline \multicolumn{5}{|c|}{ LUX i-Amylose-3, EA/DCM 9:1, $1 \mathrm{~mL} / \mathrm{min}$, detection at $640 \mathrm{~nm} ;$} \\
\hline & Area 1 & Area 2 & $\% 1$ & $\% 2$ \\
\hline $\begin{array}{c}\text { Pr-SQA* } \\
\text { mixture (SS, RR, } \\
\text { RS), left }\end{array}$ & 193480 & 627326 & 24.2 & 75.8 \\
\hline $\begin{array}{c}\text { SS-Pr-SQA* } \\
\text { right }\end{array}$ & 10844199 & 74401 & 99.3 & 0.7 \\
\hline
\end{tabular}

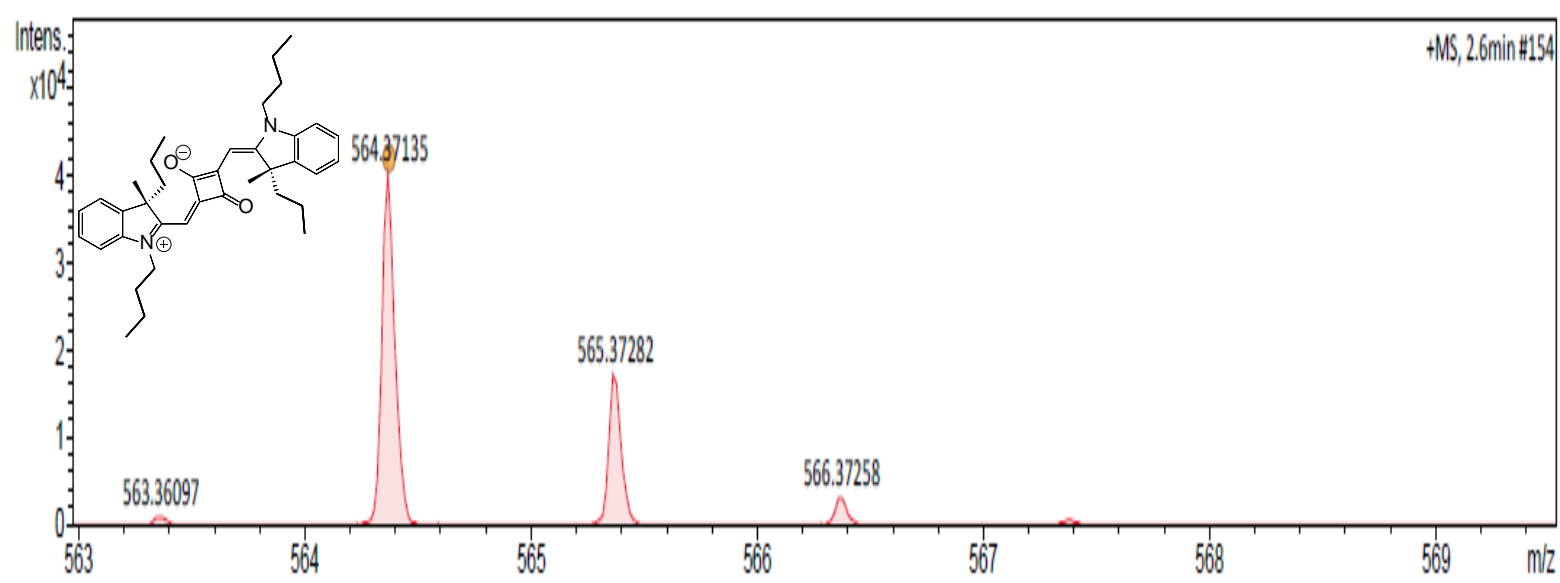

Figure S22. HRMS (ESI) spectrum of Pr-SQA*. 


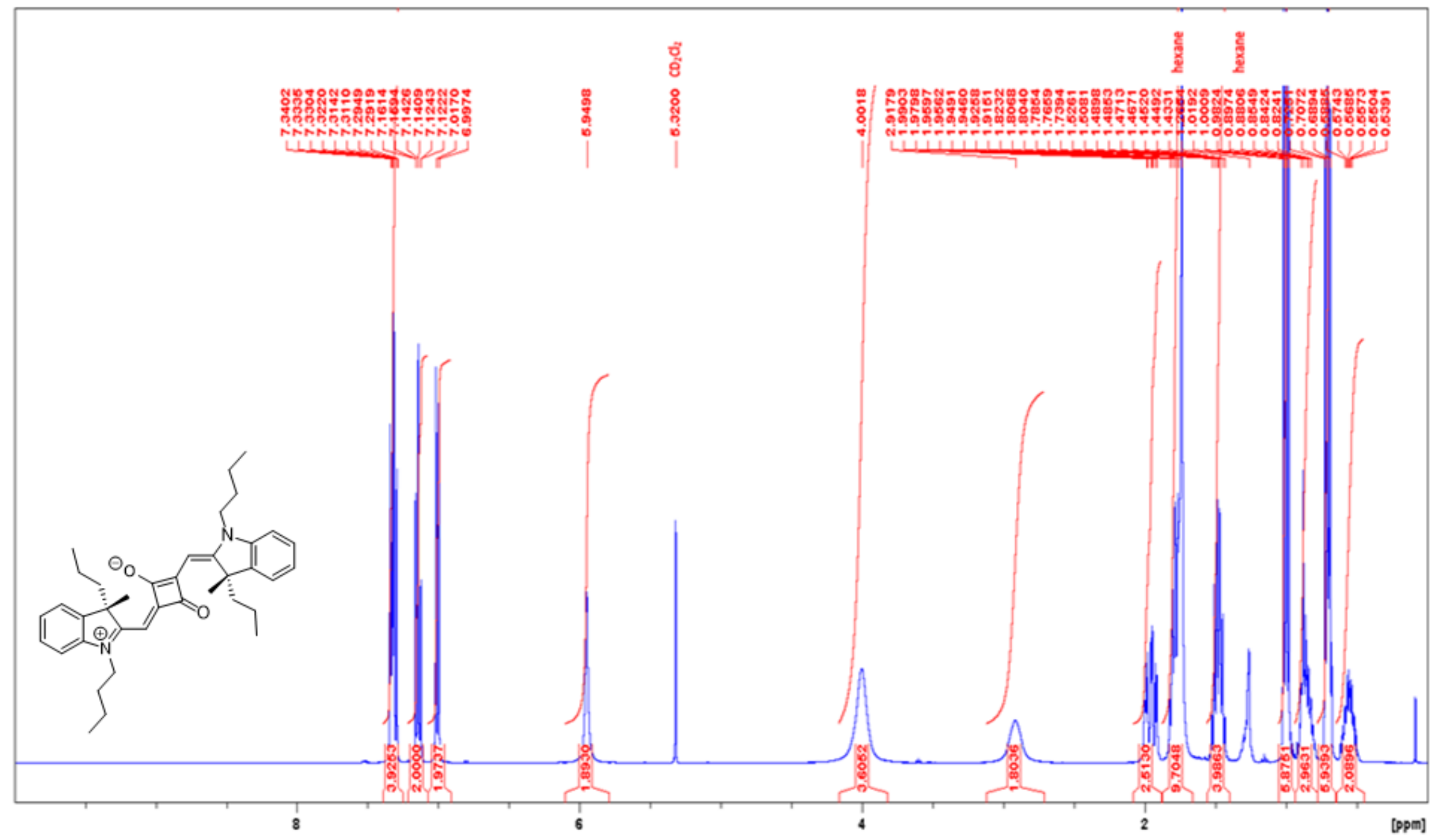

Figure S23. ${ }^{1} \mathrm{H}$ NMR spectrum $\left(400 \mathrm{MHz}, \mathrm{CD}_{2} \mathrm{Cl}_{2}\right)$ of Pr-SQA* 


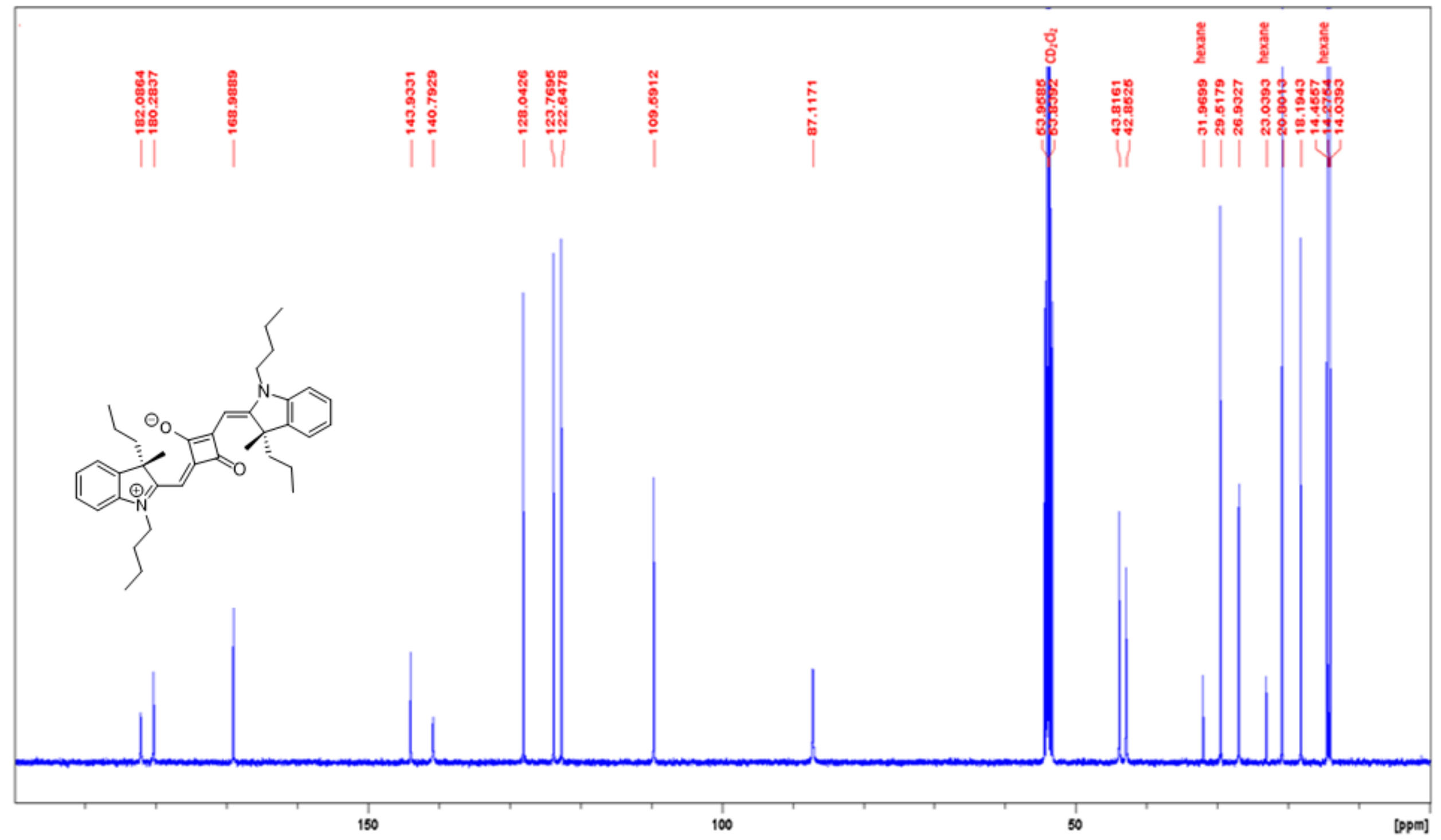

Figure S24. $\left.{ }^{13} \mathrm{C}^{1}{ }^{1} \mathrm{H}\right\} \mathrm{NMR}$ spectrum $\left(100 \mathrm{MHz}, \mathrm{CD}_{2} \mathrm{Cl}_{2}\right)$ of Pr-SQA*. 
$\mathrm{Ph}-\mathrm{SQB}^{*}$
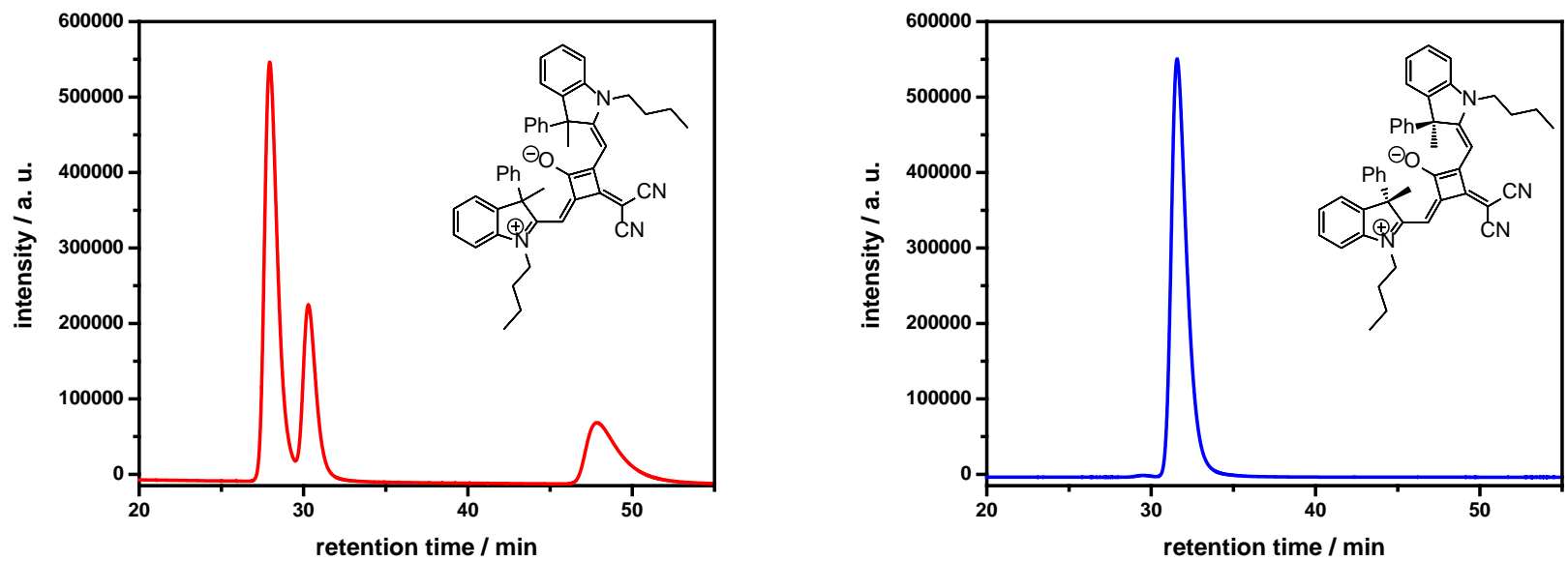

Figure S25. Chromatograms of Ph-SQB*. Left: mixture of stereoisomers, right: SS-Ph-SQB*.

Table S8. Data obtained from analytical HPLC of Ph-SQB*

\begin{tabular}{|c|c|c|c|c|c|c|}
\hline \multicolumn{7}{|c|}{ LUX i-Amylose-3, Hexane/DCM/i-PrOH 19:8:1, $1 \mathrm{~mL} / \mathrm{min}$, detection at $700 \mathrm{~nm} ;$} \\
$t(1)=27.9 \mathrm{~min} ;(2)=30.3 \mathrm{~min}, t(3)=47.8 \mathrm{~min}$
\end{tabular}

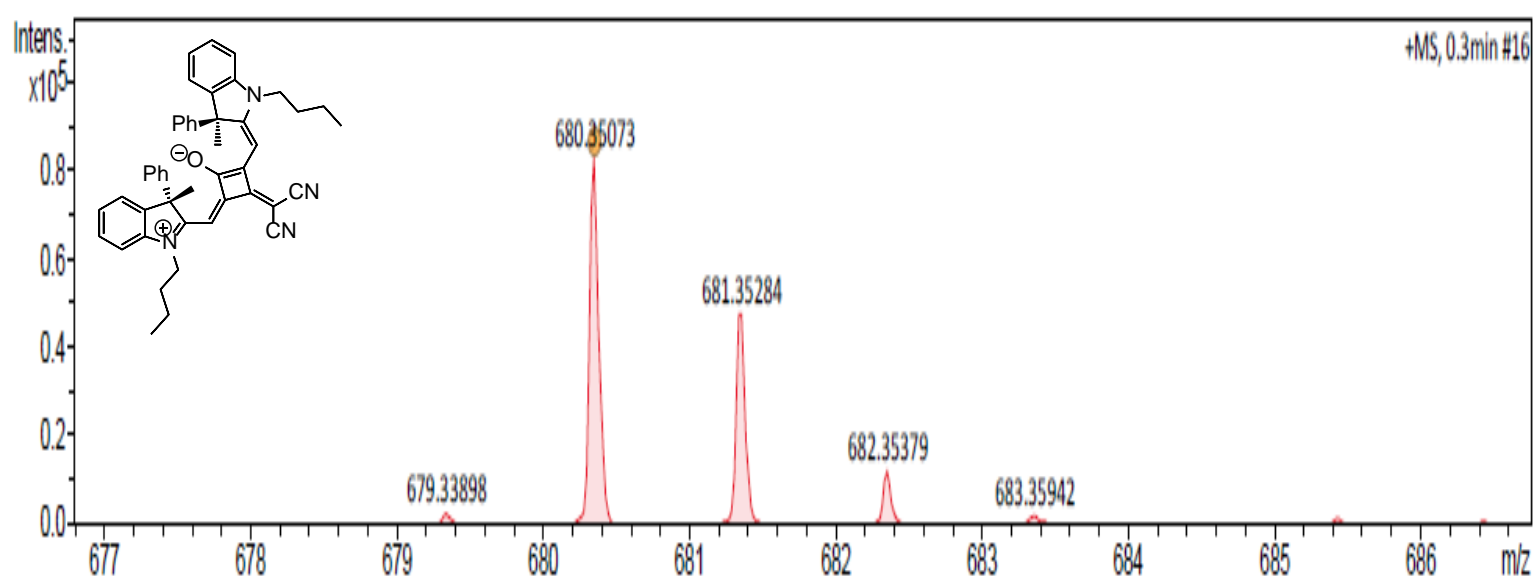

Figure S26. HRMS (ESI) spectrum of Ph-SQB*. 


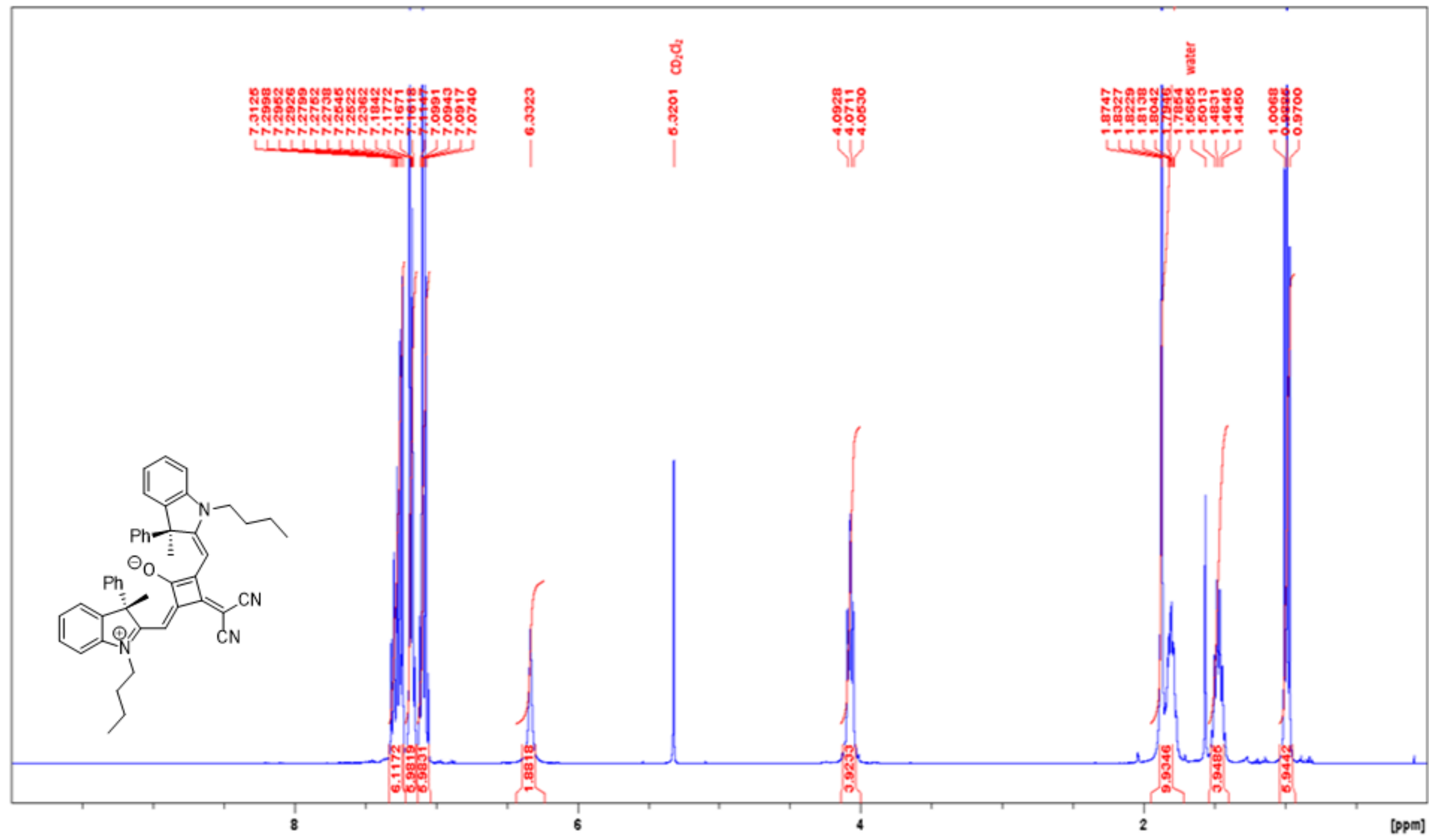

Figure S27. ${ }^{1} \mathrm{H}$ NMR spectrum $\left(400 \mathrm{MHz}, \mathrm{CD}_{2} \mathrm{Cl}_{2}\right)$ of Ph-SQB*. 


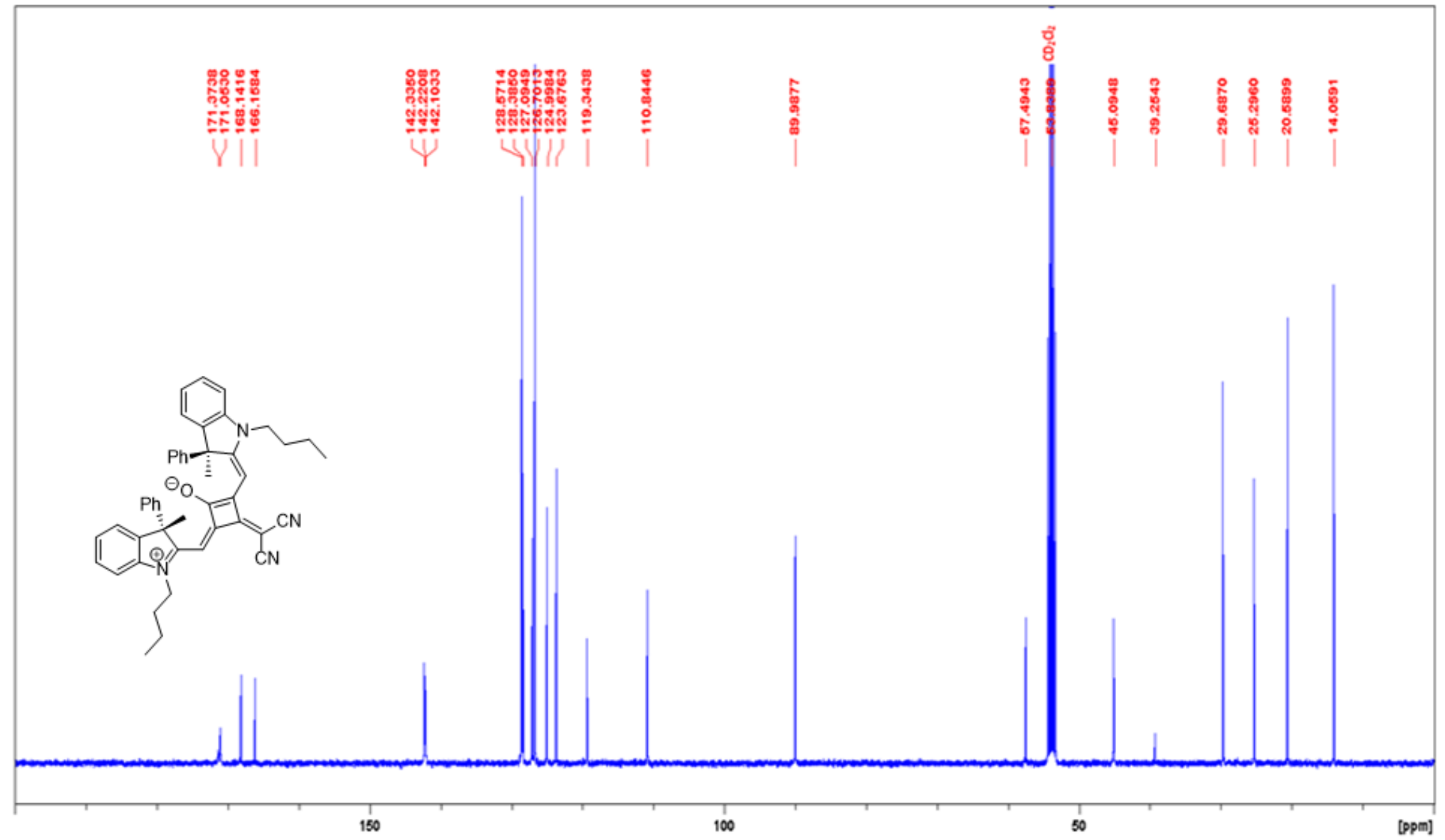

Figure S28. ${ }^{13} \mathrm{C}\left\{{ }^{1} \mathrm{H}\right\} \mathrm{NMR}$ spectrum $\left(100 \mathrm{MHz}, \mathrm{CD}_{2} \mathrm{Cl}_{2}\right)$ of Ph-SQB* 
Ph-SQA*
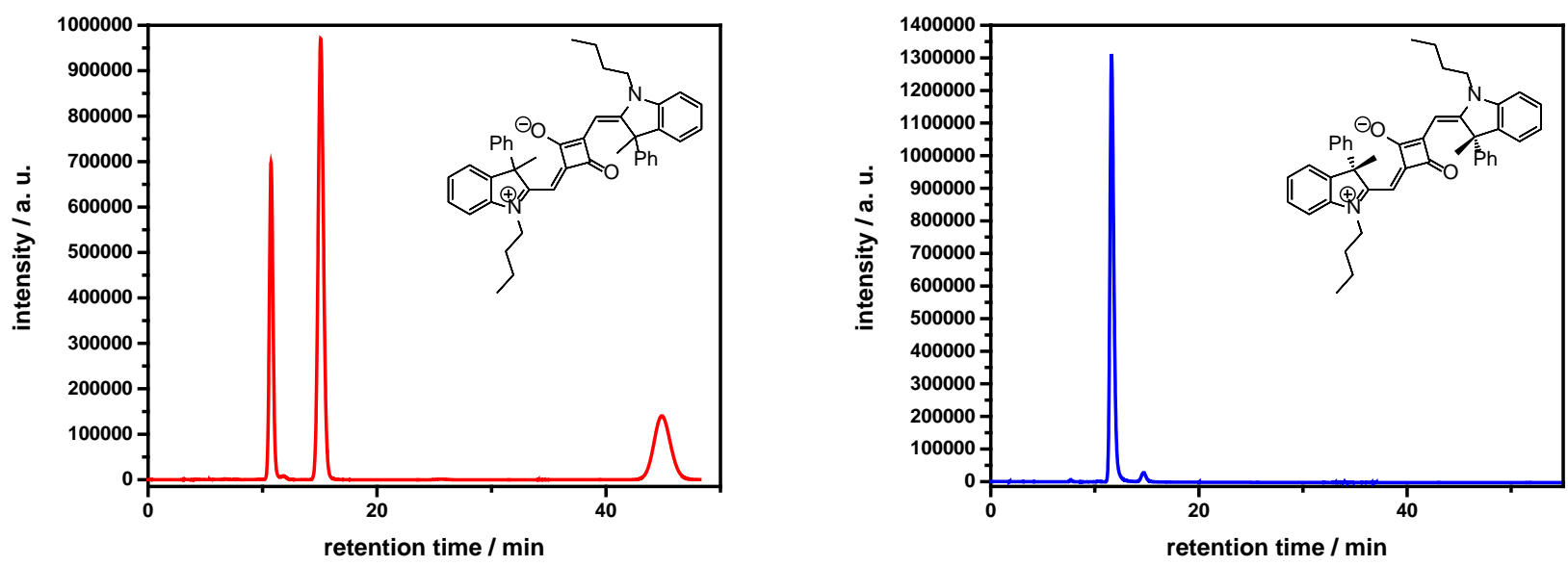

Figure S29. Chromatograms of Ph-SQA*. Left: mixture of stereoisomers, right: SS-Ph-SQA*.

Table S9. Data obtained from analytical HPLC of Ph-SQA*

\begin{tabular}{|c|c|c|c|c|c|c|}
\hline \multicolumn{7}{|c|}{ LUX $i$-Amylose-3, EA/DCM 9:1, $1 \mathrm{~mL} / \mathrm{min}$, detection at $640 \mathrm{~nm} ;$} \\
\hline & Area 1 & Area 2 & Area 3 & $\% 1$ & $\% 2$ & $\% 3$ \\
\hline $\begin{array}{c}\text { Ph-SQA* } \\
\text { mixture (SS, } \\
\text { RR, RS), left }\end{array}$ & 265915 & 539078 & 241850 & 25.4 & 51.5 & 23.1 \\
\hline $\begin{array}{c}\text { SS- } \\
\text { Ph-SQA* } \\
\text { right }\end{array}$ & 573911 & 14519 & - & 97.53 & 2.47 & - \\
\hline
\end{tabular}

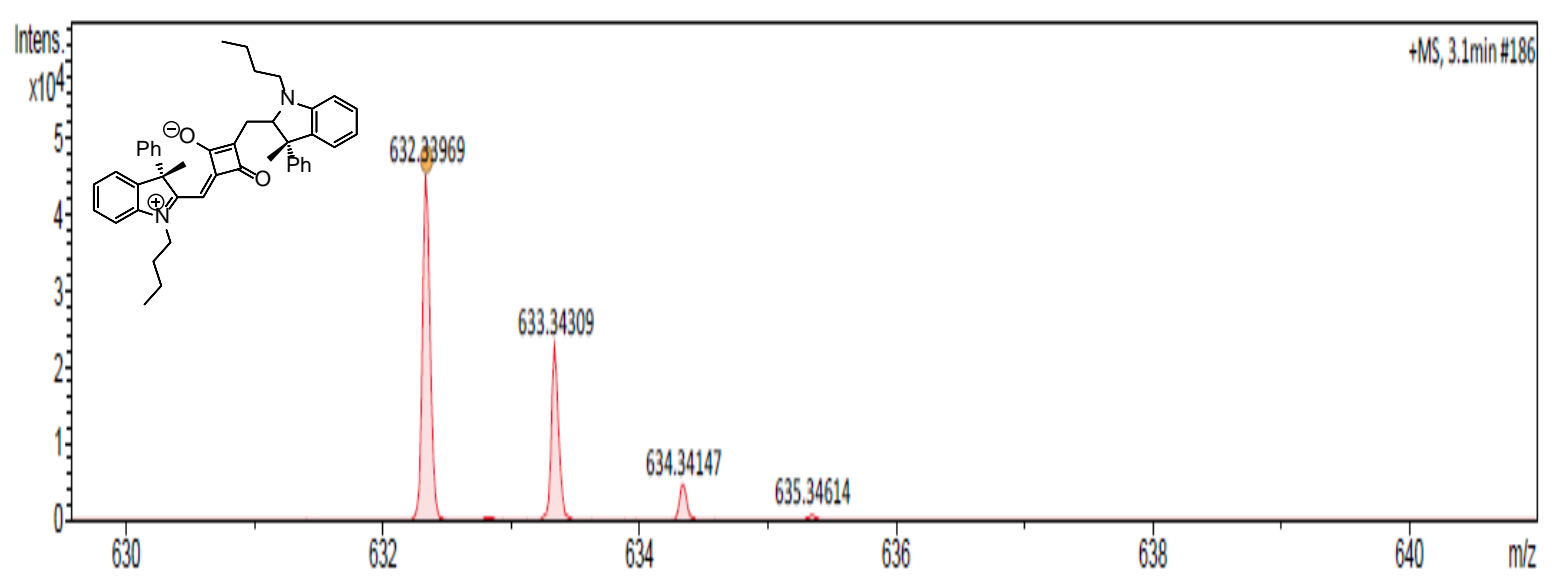

Figure S30. HRMS (ESI) spectrum of Ph-SQA*. 


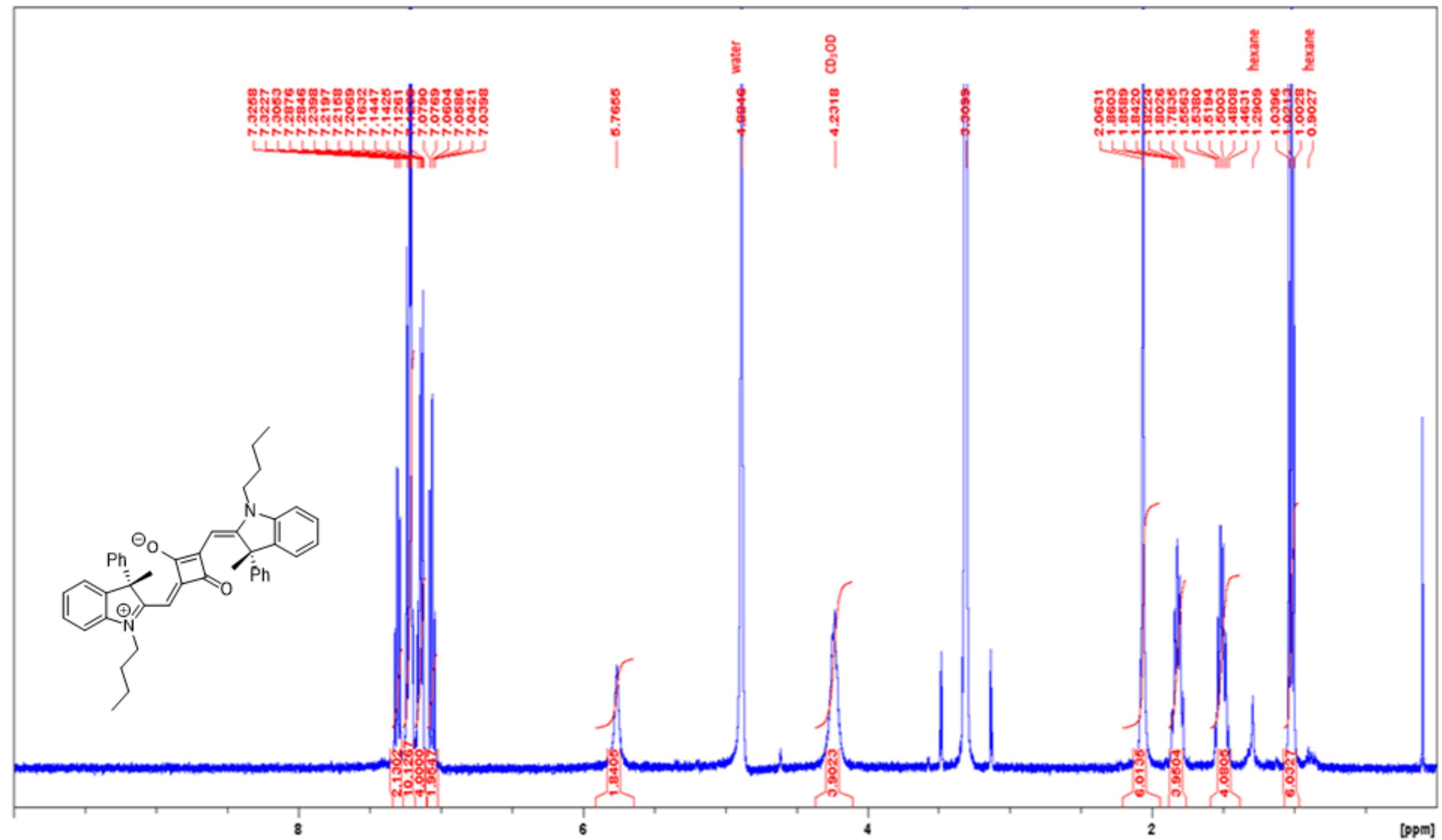

Figure S31. ${ }^{1} \mathrm{H}$ NMR spectrum $\left(400 \mathrm{MHz}, \mathrm{CD}_{3} \mathrm{OD}\right)$ of Ph-SQA*. 


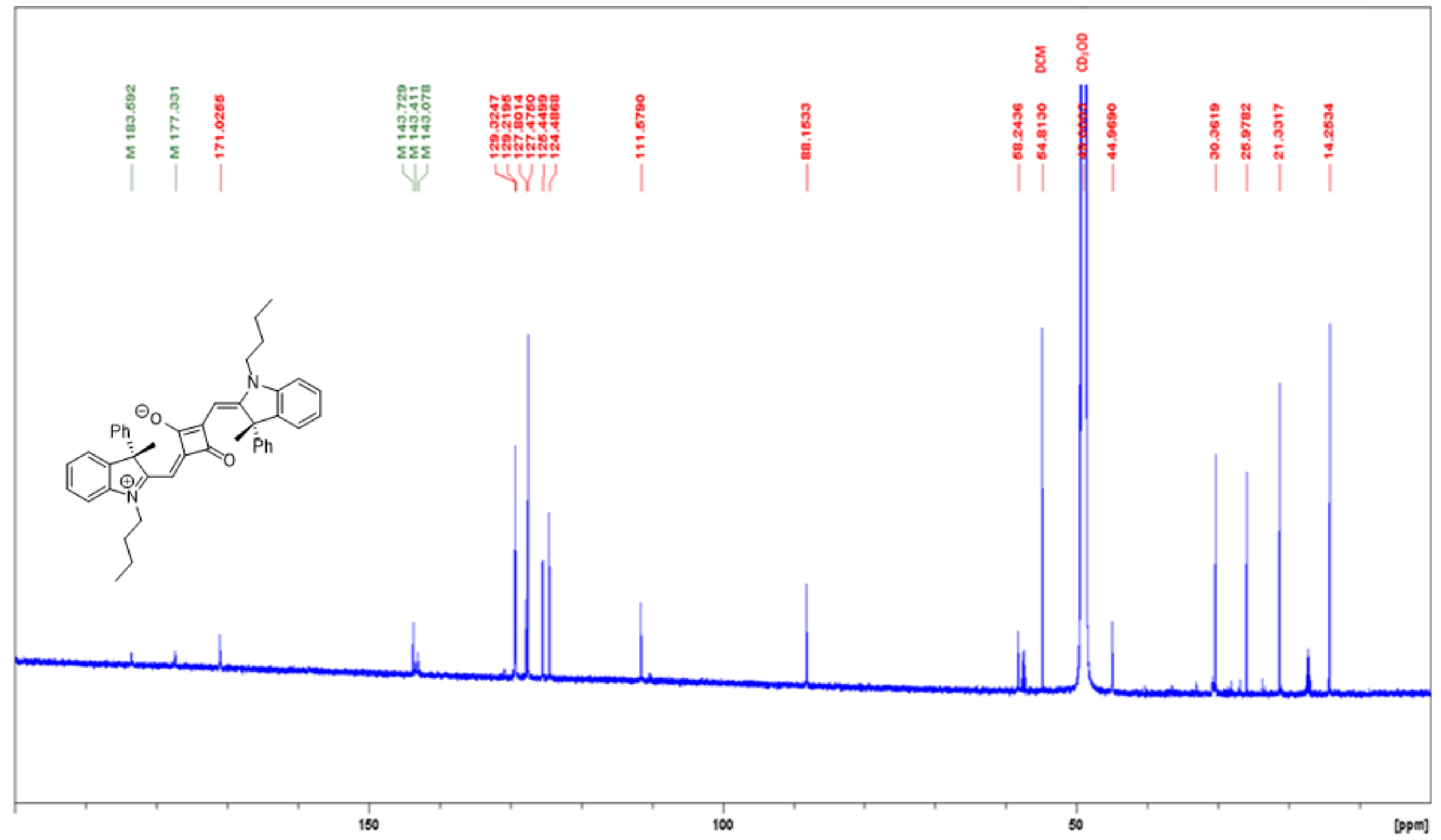

Figure S32. ${ }^{13} \mathrm{C}\left\{{ }^{1} \mathrm{H}\right\} \mathrm{NMR}$ spectrum (150 MHz, CD 3 OD) of Ph-SQA* 


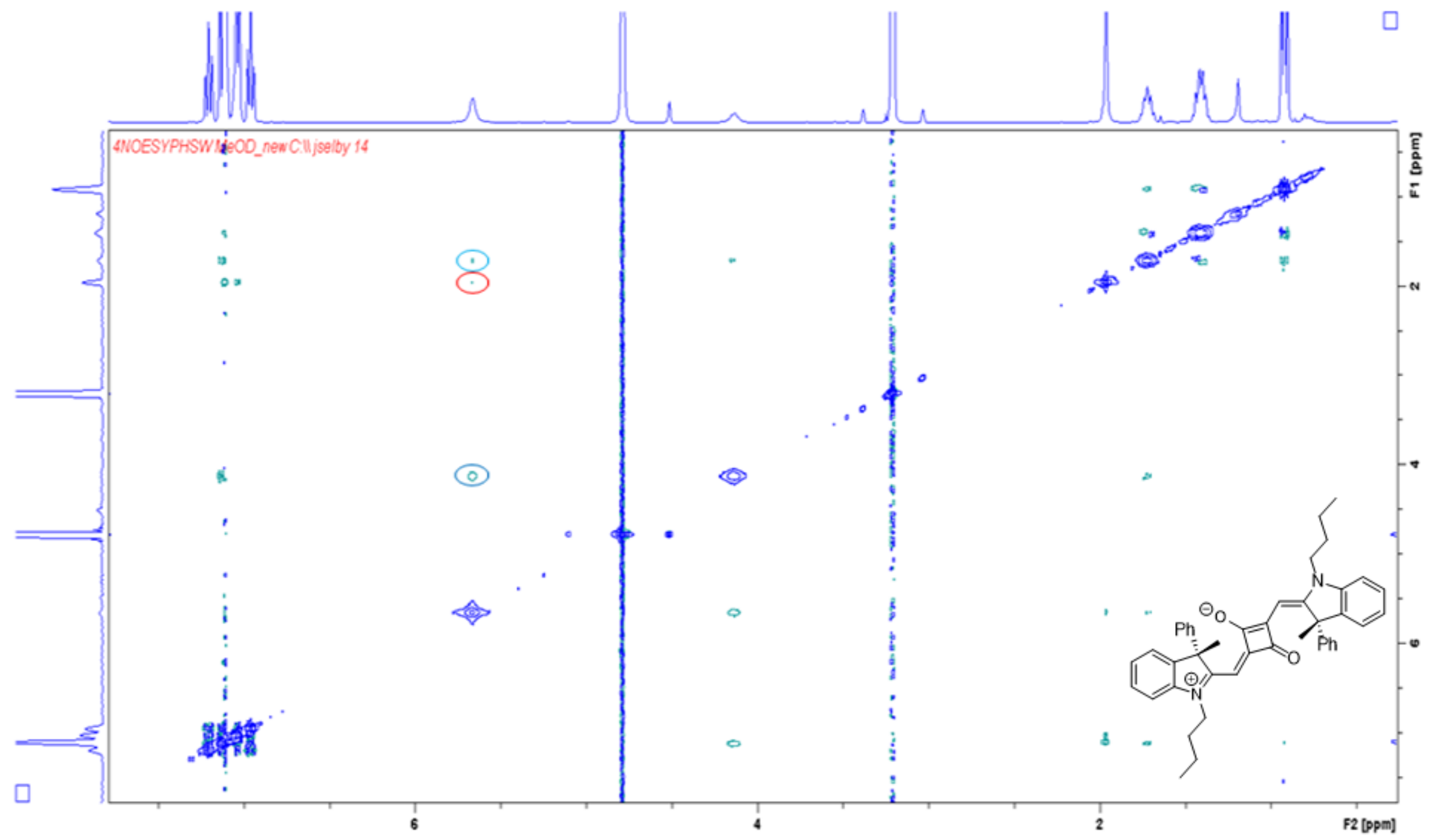

Figure S33. Full NOESY spectrum of Ph-SQA* $\left(400 \mathrm{MHz}\right.$, methanol- $\mathrm{d}_{5}$, mixing time $=0.6 \mathrm{~s}$ ). 


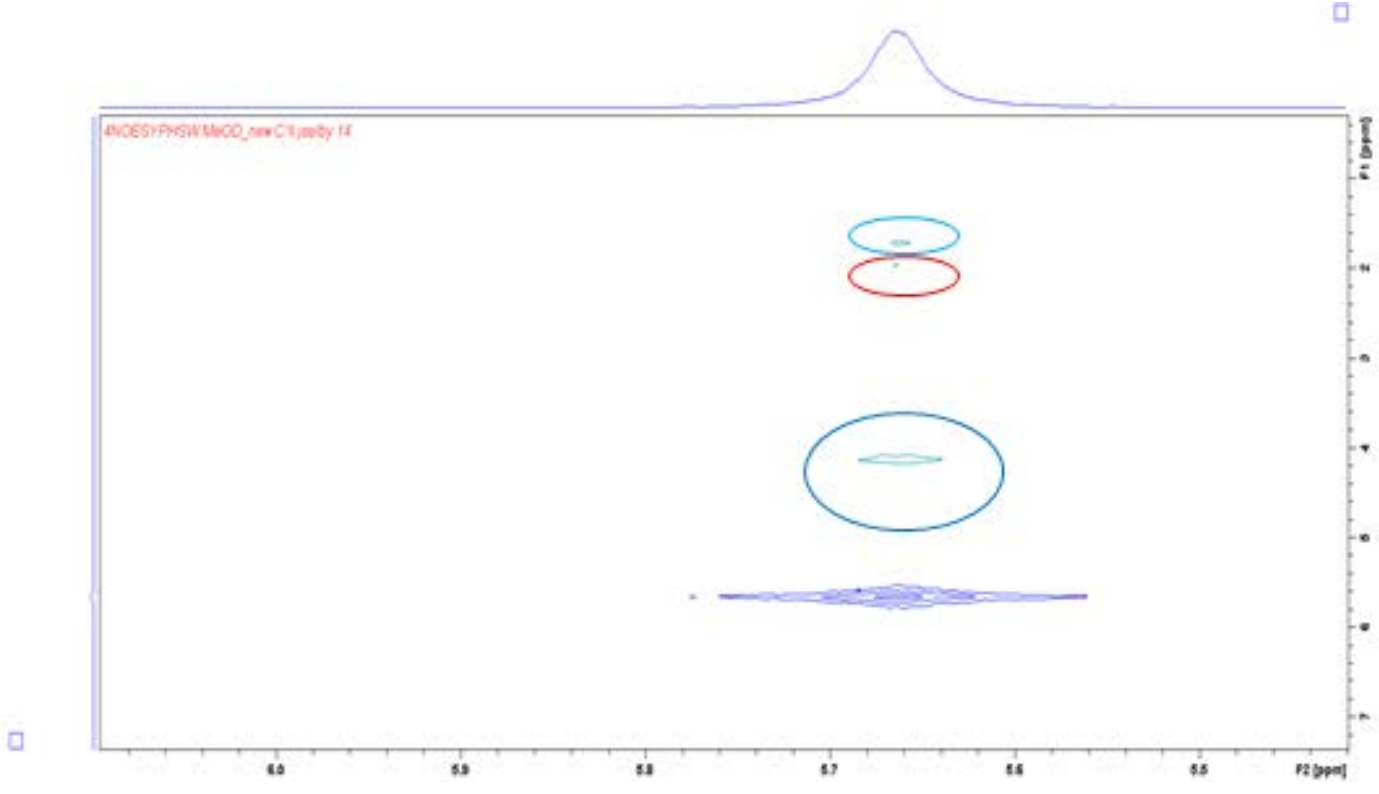

Figure S 34. Magnified section of the NOESY-spectrum of Ph-SQA* showing the cross peaks of the methine proton (green in Figure S35) with the methyl group at C(3) (red), as well as the first (dark blue) and second (light blue) methylene groups of the alkyl side chain.

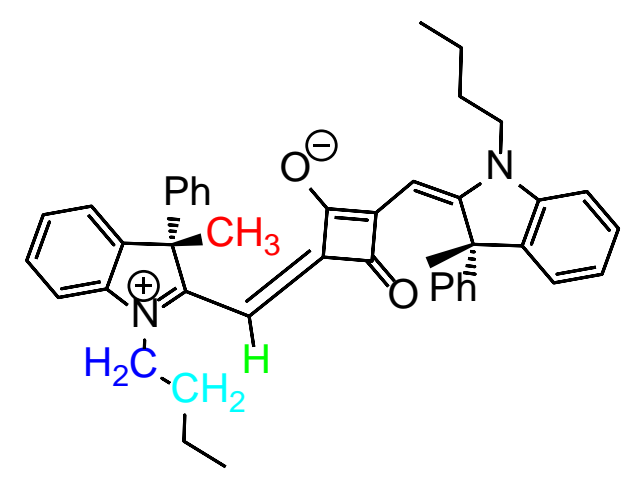

Figure S35. Structure of Ph-SQA* with the relevant protons marked in color.

Table S10. Atom distances in the crystal structure and the DFT-optimized structure of Ph-SQB*, relative NOESY crosssignal intensities and calculated atom distances using eq. 7

\begin{tabular}{|c|c|c|c|c|}
\hline & $\begin{array}{c}d(\text { Ph-SQB* cryst }) \\
/ \AA\end{array}$ & $\begin{array}{c}d(\text { Ph-SQB* calcd }) \\
/ \AA\end{array}$ & $\begin{array}{c}\text { Rel. Integral } \\
\text { NOESY }\end{array}$ & $\begin{array}{c}d\left(\text { Ph-SQA }^{*}\right)_{\text {NOESY }} \\
/ \AA\end{array}$ \\
\hline $\mathrm{H}-\mathrm{CH}_{3}$ & 3.87 & 4.23 & 0.1438 & 3.08 \\
\hline $\mathrm{H}-\mathrm{CH}_{2}$ & 2.07 & 2.18 & 1.0000 & $2.13^{*}$ \\
\hline $\mathrm{H}-\mathrm{CH}_{2}$ & 2.51 & - & 0.2414 & 2.69 \\
\hline
\end{tabular}

* used as the reference distance (average of crystal structure and calculated structure) 


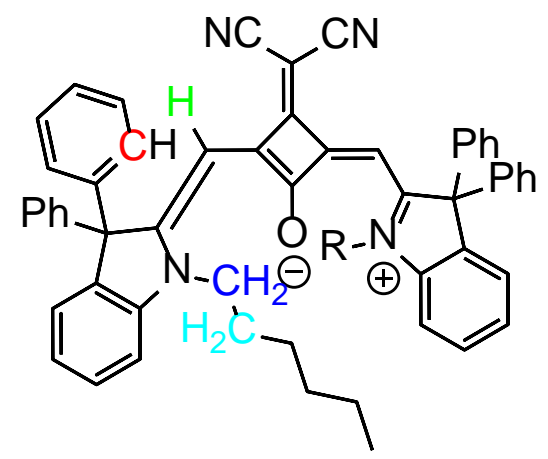

Figure S36. Structure of TPh-SQB with the relevant protons marked in color.

Table S11. Atom distances in the crystal structure of TPh-SQB.

\begin{tabular}{|c|c|}
\hline & d (TPh-SQB cryst) \\
\hline $\mathrm{H}-\mathrm{CH}$ & $2.75,3.85^{*}$ \\
\hline $\mathrm{H}-\mathrm{CH}_{2}$ & 3.83 \\
\hline $\mathrm{H}-\mathrm{CH}_{2}$ & 3.49 \\
\hline
\end{tabular}

*because of structural torsion, different values were obtained for the carbon atoms of the phenyl groups.

The proton distances were calculated using the following equation: ${ }^{8}$

$$
d=d_{r e f}\left(\frac{a_{r e f}}{a}\right)
$$

Where $d$ is the distance between two protons, $d_{\text {ref }}$ is the reference distance, $a_{\text {ref }}$ the relative integral of the reference NOESY cross signal and $a$ the relative integral of the NOESY cross signal corresponding to the proton distance to be determined. 
For the evaluation of proton distances, the bridge methine group (green in Figures S35 and S36) was chosen as the main reference point. As can be seen in Table S10, the calculated proton distances using eq. 7 match the distances in the crystal structure and the DFToptimized structure for Ph-SQB* (which is known to have the expected geometry shown in Figure 1) quite well for the first two methylene groups of the alkyl side chain. Also, the NOESY data indicates that the distance of the methyl group protons at the 3-position is significantly larger than that of the aforementioned alkyl chain portons, which is also true for both of the Ph-SQB* structures. When examining the data from the crystal structure of TPh-SQB (Table S5), it can be seen that the distances of the alkyl chain protons are markedly larger than those in Ph-SQB*. Also, the distances of the phenyl group (attached at C(3)) carbon atoms are roughly the same or even shorter compared to the first two methylene groups of the alkyl chain. It can be therefore concluded that Ph-SQA* possesses the same standard squaraine geometry as depicted in

Fig.

1. 
SQB-R*

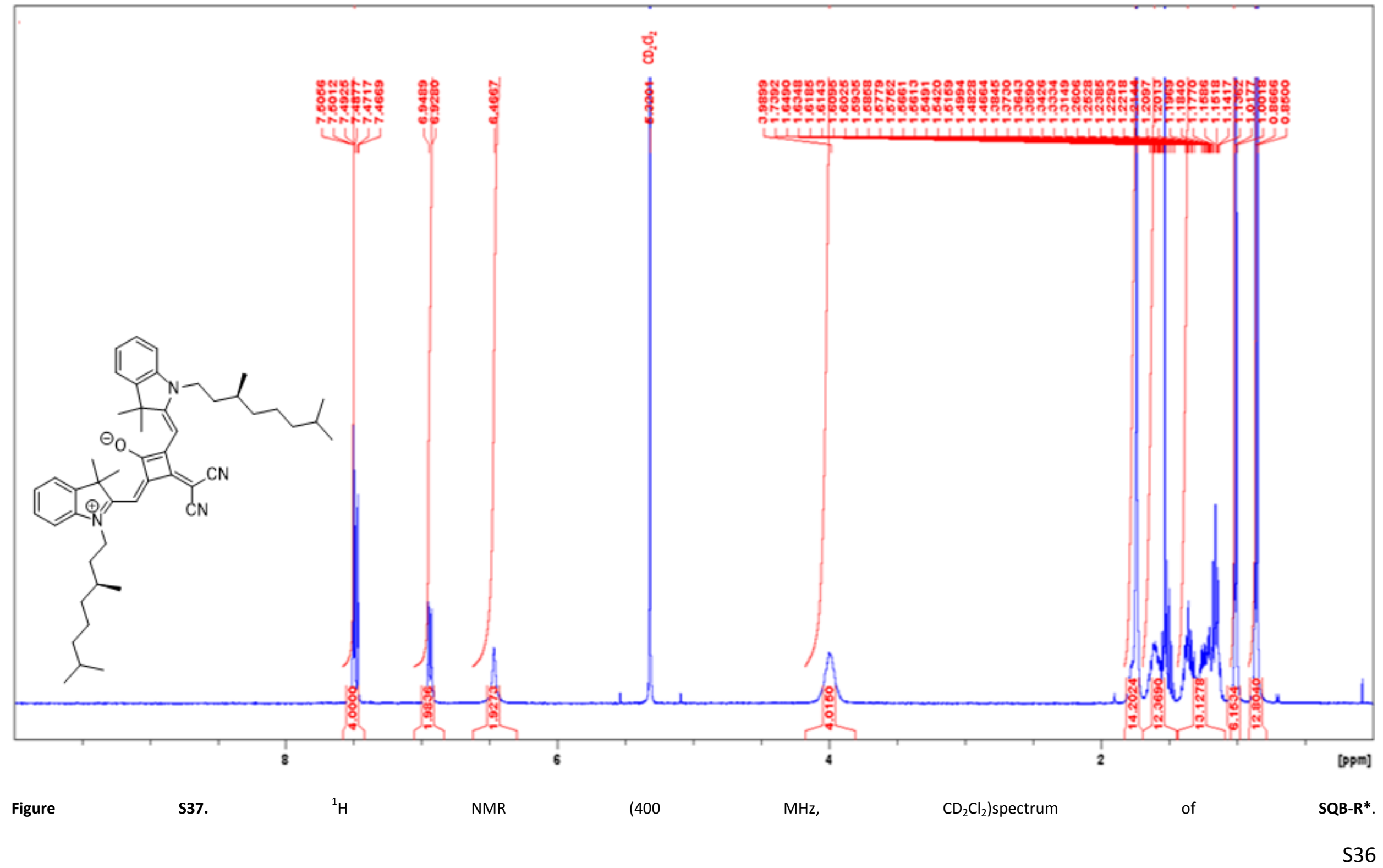




\section{Computational data}

All DFT- and TDDFT calculations were performed on the B3LYP/6-31G* level using the software package Gaussian $09^{9}$. The geometries were optimized at that level of theory and frequency analysis revealed no imaginary frequencies. The TD calculations were then performed using these stationary geometries. The xyz-coordinates with the corresponding total energies of the optimized structures are listed below.

\section{Pr-SQA*}

\begin{tabular}{|c|c|c|c|}
\hline 6 & 2.031252000 & $7.7550460 \odot \odot$ & $-\odot .4323040 \odot \odot$ \\
\hline 6 & 3.392845000 & 7.446479000 & -0.462643000 \\
\hline 6 & 3.834194000 & 6.118516000 & $-\odot .465223000$ \\
\hline 6 & 2.865746000 & 5.117044000 & -0.435446000 \\
\hline 6 & 1.497802000 & 5.409032000 & -0.404741000 \\
\hline 6 & 1.075015000 & 6.730236000 & -0.403624000 \\
\hline 7 & 3.029336000 & 3.718964000 & -0.434004000 \\
\hline 6 & 1.819733000 & 3.066389000 & -0.410447000 \\
\hline 6 & ๑. 699360000 & 4.115716000 & -0.389051000 \\
\hline 6 & 1.761731000 & 1.682684000 & $-\odot .41547400 \odot$ \\
\hline 6 & ๑. 681681000 & $\odot .791170000$ & -0.407735000 \\
\hline 6 & $-\odot .7932190 \odot \odot$ & 0.678336000 & $-\odot .410 \odot 40 \odot \odot \odot$ \\
\hline 6 & -0.681681000 & -0.791170000 & -0.407735000 \\
\hline 6 & ๑ . 793219000 & -0.678336000 & -0.410040000 \\
\hline 6 & -1.761731000 & -1.682684000 & -0.415474000 \\
\hline 6 & -1.819733000 & -3.066389000 & -0.410447000 \\
\hline 6 & $-\odot .6993600 \odot \odot$ & -4.115716000 & -0.389051000 \\
\hline 6 & -1.497802000 & -5.409032000 & -0.404741000 \\
\hline 6 & -2.865746000 & -5.117044000 & $-\odot .435446000$ \\
\hline 7 & -3.029336000 & -3.718964000 & -0.434004000 \\
\hline 6 & -1.075015000 & -6.730236000 & -0.403624000 \\
\hline 6 & -2.031252000 & -7.755046000 & -0.432304000 \\
\hline 6 & -3.392845000 & -7.446479000 & -0.462643000 \\
\hline 6 & $-3.83419400 \odot$ & -6.118516000 & $-\odot .46522300 \odot$ \\
\hline 6 & -0.182806000 & 4.011585000 & -1.660008000 \\
\hline 6 & $-4.31570100 \odot$ & $-3.04530400 \odot$ & $-\odot .4628490 \odot \odot$ \\
\hline 6 & 4.315701000 & 3.045304000 & -0.462849000 \\
\hline 8 & 1.761731000 & -1.440704000 & -0.416133000 \\
\hline 8 & -1.761731000 & 1.440704000 & -0.416133000 \\
\hline 6 & 0.182806000 & -4.011585000 & -1.660008000 \\
\hline 6 & $-\odot .19993100 \odot$ & $4.01066400 \odot$ & $\odot .879501000$ \\
\hline 6 & 0.536577000 & 4.006645000 & 2.224594000 \\
\hline 6 & -0.433078000 & 3.964142000 & 3.410945000 \\
\hline 6 & ๑. 199931000 & -4.010664000 & ๑. 879501000 \\
\hline 6 & -0.536577000 & -4.006645000 & 2.224594000 \\
\hline 6 & 0.433078000 & -3.964142000 & 3.410945000 \\
\hline 1 & 1.711405000 & 8.79 & -0.431456000 \\
\hline
\end{tabular}




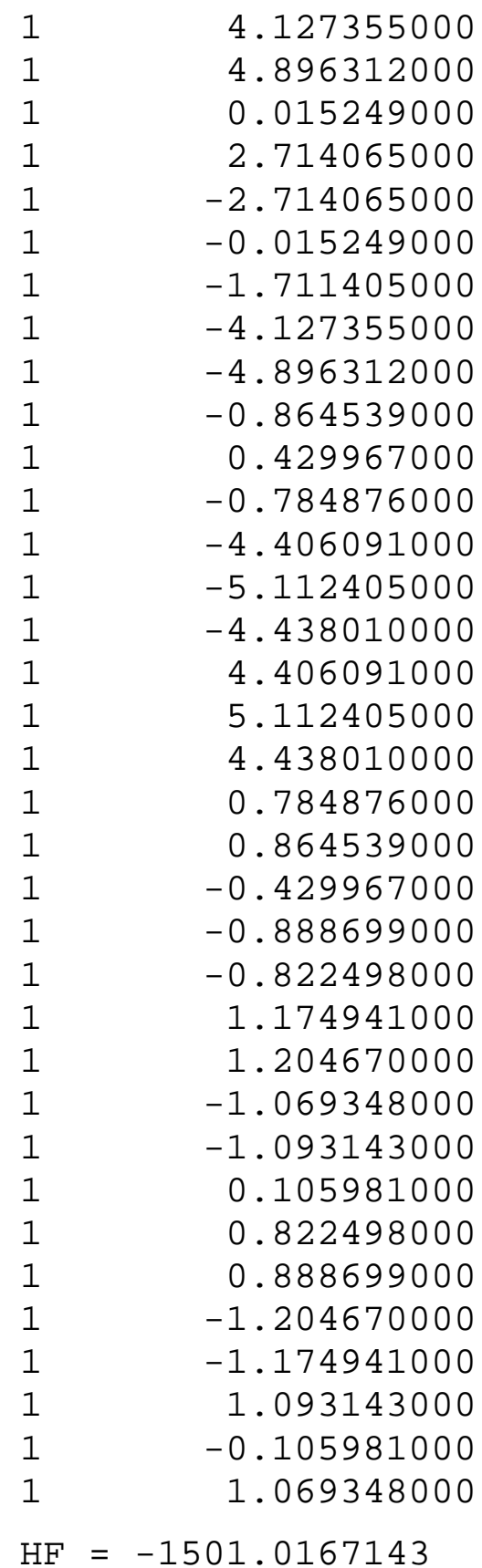

8.246720000

5.897035000

6.970937000

1.155303000

$-1.155303000$

$-6.970937000$

$-8.792945000$

$-8.246720000$

$-5.897035000$

4.868865000

4.028317000

3. 100777000

$-2.420967000$

$-3.788071000$

$-2.409023000$

2. 420967000

3. 788071000

2.409023000

$-3.100777000$

$-4.868865000$

$-4.028317000$

4.867154000

3. 115940000

4.896456000

3. 136485000

3. 072077000

4.840497000

3.948433000

$-3.115940000$

$-4.867154000$

$-3.136485000$

$-4.896456000$

$-4.840497000$

$-3.948433000$

$-3.072077000$
$-0.485307000$

- 0.489987000

$-0.381069000$

$-0.430398000$

$-0.430398000$

- $\odot .381069000$

$-0.431456000$

- $\odot .485307000$

$-0.489987000$

$-1.696234000$

$-2.567650000$

$-1.632416000$

$-1.358641000$

$-0.471431000$

0.420535000

$-1.358641000$

$-0.471431000$

๑. 420535000

$-1.632416000$

$-1.696234000$

$-2.567650000$

0.847159000

$\odot .779790000$

2. 307440000

2. 273149000

3. 370146000

3. 415511000

4.365218000

0.779790000

$\odot .847159000$

2. 273149000

2. 307440000

3. 415511000

4. 365218000

3. 370146000

\section{Ph-SQA*}

$\begin{array}{ll}6 & 1.96011900 \odot \\ 6 & 3.292301000 \\ 6 & 3.72912300 \odot \\ 6 & 2.78521000 \odot \\ 6 & 1.44861200 \odot \\ 6 & 1.028747000 \\ 7 & 2.94976300 \odot \\ 6 & 1.77268800 \odot \\ 6 & 0.66183400 \odot \\ 6 & 1.726243000 \\ 6 & 0.66183400 \odot\end{array}$

7.750946000

7.488321000

6.186313000

5. 163093000

5.412069000

6.705585000

3. 783253000

3. 094282000

4.104700000

1. 717221000

๑. 806907000
$-0.273367000$

$-0.600889000$

$-0.870320000$

- 0.804576000

$-0.477922000$

- $\odot . ~ 209056000$

$-1.028915000$

$-0.851944000$

$-0.504651000$

$-0.964568000$

$-\odot .925517000$ 


\begin{tabular}{|c|c|c|c|}
\hline 6 & $-\odot .81058300 \odot$ & $\odot .659584000$ & $-\odot .95987300 \odot$ \\
\hline 6 & $-\odot .66183400 \odot$ & $-\odot .80690700 \odot$ & $-\odot .9255170 \odot \odot$ \\
\hline 6 & ๑ . 81058300० & $-\odot .65958400 \odot$ & $-\odot .95987300 \odot$ \\
\hline 6 & -1.726243000 & -1.717221000 & -0.964568000 \\
\hline 6 & -1.772688000 & -3.094282000 & -0.851944000 \\
\hline 6 & $-\odot .661834000$ & $-4.10470 \odot \odot \odot \odot$ & -0.504651000 \\
\hline 6 & -1.448612000 & -5.412069000 & -0.477922000 \\
\hline 6 & $-2.78521000 \odot$ & $-5.16309300 \odot$ & $-\odot .8045760 \odot \odot$ \\
\hline 7 & -2.949763000 & -3.783253000 & -1.028915000 \\
\hline 6 & $-1.02874700 \odot$ & $-6.70558500 \odot$ & $-\odot .209056000$ \\
\hline 6 & -1.960119000 & -7.750946000 & -0.273367000 \\
\hline 6 & $-3.29230100 \odot$ & -7.488321000 & $-\odot .6008890 \odot \odot$ \\
\hline 6 & -3.729123000 & -6.186313000 & -0.870320000 \\
\hline 6 & -0.379845000 & 4.163219000 & -1.649761000 \\
\hline 6 & $-4.20383100 \odot$ & -3.161232000 & $-1.41483000 \odot$ \\
\hline 6 & 4.203831000 & 3.161232000 & -1.414830000 \\
\hline 8 & 1.800963000 & $-1.38671700 \odot$ & $-1.0417810 \odot \odot$ \\
\hline 8 & -1.800963000 & 1.386717000 & -1.041781000 \\
\hline 1 & 1.645447000 & 8.768647000 & $-\odot .0619280 \odot \odot$ \\
\hline 1 & $4.0083250 \odot \odot$ & 8.304324000 & -0.644034000 \\
\hline 1 & 4.769887000 & 5.998138000 & -1.113615000 \\
\hline$\overline{1}$ & $-\odot .0 \odot 555300 \odot$ & 6.903376000 & $\odot .05927200 \odot$ \\
\hline 1 & 2.680458000 & 1. 207830000 & -1.091992000 \\
\hline$\overline{1}$ & -2.680458000 & $-1.20783000 \odot$ & -1.091992000 \\
\hline 1 & $\odot .005553000$ & -6.903376000 & ๑. 059272000 \\
\hline 1 & -1.645447000 & -8.768647000 & $-\odot .0619280 \odot \odot$ \\
\hline 1 & -4.008325000 & -8.304324000 & -0.644034000 \\
\hline 1 & -4.769887000 & -5.998138000 & -1.113615000 \\
\hline 1 & -1.074853000 & 4.991453000 & -1.474093000 \\
\hline 1 & 0.129311000 & 4.351204000 & -2.600553000 \\
\hline$\overline{1}$ & $-\odot .948219000$ & 3.232265000 & -1.715713000 \\
\hline 1 & -4.053506000 & -2.523555000 & -2.291606000 \\
\hline 1 & -4.928083000 & -3.935385000 & -1.667523000 \\
\hline 1 & -4.608857000 & -2.547557000 & -0.601312000 \\
\hline 1 & 4.053506000 & 2.523555000 & -2.291606000 \\
\hline 1 & 4.928083000 & 3.935385000 & -1.667523000 \\
\hline 1 & 4.608857000 & 2.547557000 & -0.601312000 \\
\hline 6 & ๑ . 054539000 & 3.820067000 & 0.884434000 \\
\hline 6 & -1.314925000 & 3.622666000 & 1.082579000 \\
\hline 6 & $\odot .90208000 \odot$ & 3.796827000 & $2.00393100 \odot$ \\
\hline 6 & -1.822908000 & 3.412815000 & 2.368416000 \\
\hline 6 & ๑ . 397983000 & 3.582225000 & 3. $28359200 \odot$ \\
\hline 6 & $-\odot .97352300 \odot$ & 3.392912000 & $3.47200100 \odot$ \\
\hline 1 & -1.991484000 & 3.591274000 & $\odot .23887600 \odot$ \\
\hline 1 & 1.970002000 & 3.954145000 & $1.87369100 \odot$ \\
\hline 1 & -2.890531000 & 3.255757000 & 2.497966000 \\
\hline 1 & 1.075242000 & 3.565445000 & 4.133649000 \\
\hline 1 & -1.371930000 & 3.226705000 & 4.469485000 \\
\hline 6 & ๑ . 379845000 & $-4.16321900 \odot$ & -1.649761000 \\
\hline 1 & ๑ . 948219000 & -3.232265000 & -1.715713000 \\
\hline 1 & 1.074853000 & -4.991453000 & -1.474093000 \\
\hline
\end{tabular}




$\begin{array}{lr}1 & -\odot .12931100 \odot \\ 6 & -\odot .05453900 \odot \\ 6 & -\odot .9020800 \odot \odot \\ 6 & 1.31492500 \odot \\ 6 & -\odot .39798300 \odot \\ 6 & 1.8229080 \odot \odot \\ 6 & 0.97352300 \odot \\ 1 & -1.9700 \odot 20 \odot \odot \\ 1 & 1.99148400 \odot \\ 1 & -1.07524200 \odot \\ 1 & 2.8905310 \odot \odot \\ 1 & 1.3719300 \odot \odot \\ H F= & -1727.2196371\end{array}$

\section{Pr-SQB*}

\begin{tabular}{|c|c|}
\hline 6 & 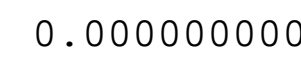 \\
\hline 6 & $\odot .0 \odot 510800 \odot$ \\
\hline 6 & ๑. . 00000000 \\
\hline 6 & - ๑ . ๑๑51080०९ \\
\hline 6 & 0.001193000 \\
\hline 6 & $-\odot .0011930 \odot$ \\
\hline 6 & 0.0255950 \\
\hline 6 & -0.02559500 \\
\hline 6 & $\odot .0 \odot \odot \odot \odot \odot \odot \odot \odot$ \\
\hline 8 & ๑. .0000000000 \\
\hline 7 & $\odot .0 \odot 16420 \odot$ \\
\hline 6 & ๑ . $0243500 \odot$ \\
\hline 6 & $\odot .075021000$ \\
\hline 6 & $\odot .07415200$ \\
\hline 6 & -0.074152000 \\
\hline 6 & -0.07502100 \\
\hline 6 & -0.02435000 \\
\hline 7 & -0.00164200 \\
\hline 6 & ๑. . 00000000 \\
\hline 6 & 0.03103000 \\
\hline 6 & ๑ . 08289000 \\
\hline 6 & $\odot .10408400$ \\
\hline 6 & -0.104084000 \\
\hline 6 & $-\odot .08289000$ \\
\hline 6 & -0.03103000 \\
\hline 6 & ๑. . 00000000 \\
\hline 6 & -0.05413200 \\
\hline 6 & 0.05413200 \\
\hline 6 & 1.34921300 \\
\hline 6 & -1.19779300 \\
\hline 6 & 1.19779300 \\
\hline 6 & -1.34921300 \\
\hline 6 & $\odot .01793400$ \\
\hline 7 & ๑. . ०339810৫ \\
\hline
\end{tabular}

$-4.351204000$

$-3.820067000$

- 3.796827000

- 3.622666000

$-3.582225000$

- 3.412815000

$-3.392912000$

$-3.954145000$

$-3.591274000$

$-3.565445000$

$-3.255757000$

$-3.226705000$
$-2.600553000$
0.884434000
2. 003931000
1.082579000
3.283592000
2. 368416000
3. 472001000
1.873691000
๑. 238876000
4.133649000
2.497966000
4.469485000

๑. . 000000000

1. 042687000

๑ . 000000000

$-1.042687000$

2. 430615000

$-2.430615000$

3.505558000

$-3.505558000$

0.000000000

๑. 000000000

4. 782676000

5.741454000

5.075733000

3. 574601000

$-3.574601000$

$-5.075733000$

$-5.741454000$

$-4.782676000$

7.131807000

7.854752000

7.205086000

5.805159000

$-5.805159000$

$-7.205086000$

$-7.854752000$

$-7.131807000$

5.113560000

$-5.113560000$

2. 902941000

2. 941596000

- 2.941596000

$-2.902941000$

1. 214969000

2. 227077000
$-2.103746000$

$-1.091006000$

$-0.035401000$

$-1.091006000$

$-1.272506000$

$-1.272506000$

$-0.389055000$

$-0.389055000$

$-3.497732000$

1.196090000

$-0.882786000$

$\odot .149457000$

1. 377838000

1.143429000

1.143429000

1. 377838000

0.149457000

$-0.882786000$

๑. 061715000

1. 259022000

2. 494551000

2. 557708000

2. 557708000

2. 494551000

1. 259022000

๑. . 061715000

- 2 . 301628000

$-2.301628000$

1.735458000

1.764827000

1. 764827000

1. 735458000

$-4.237903000$

$-4.82090900 \odot$ 


\begin{tabular}{|c|c|c|c|}
\hline 6 & -0.017934000 & -1.214969000 & -4.237903000 \\
\hline 7 & -0.033981000 & -2.227077000 & -4.820909000 \\
\hline 6 & 2.687026000 & 3.380216000 & 1.156380000 \\
\hline 6 & 3.882364000 & 2.707365000 & 1.840395000 \\
\hline 6 & -2.687026000 & -3.380216000 & 1.156380000 \\
\hline 6 & -3.882364000 & -2.707365000 & 1.840395000 \\
\hline 1 & -0.024724000 & 2.710517000 & -2.318772000 \\
\hline 1 & $\odot .024724000$ & -2.710517000 & -2.318772000 \\
\hline 1 & -0.042329000 & 7.652301000 & $-\odot .88924900 \odot$ \\
\hline 1 & ๑ . 013438000 & 8.940209000 & 1.220563000 \\
\hline 1 & ๑. 105834000 & 7.787417000 & 3.410905000 \\
\hline 1 & $\odot .142767000$ & 5.301068000 & 3.519901000 \\
\hline 1 & -0.142767000 & -5.301068000 & 3.519901000 \\
\hline 1 & -0.105834000 & - 7.787417000 & 3.410905000 \\
\hline 1 & -0.013438000 & -8.940209000 & 1.220563000 \\
\hline 1 & ๑. . 042329000 & -7.652301000 & -0.889249000 \\
\hline 1 & -0.973589000 & 4.729196000 & -2.754262000 \\
\hline 1 & $-\odot .02798600 \odot$ & 6.195821000 & -2.417811000 \\
\hline 1 & $\odot .797655000$ & 4.680334000 & -2.834226000 \\
\hline 1 & -0.797655000 & -4.680334000 & -2.834226000 \\
\hline 1 & 0.973589000 & -4.729196000 & -2.754262000 \\
\hline 1 & 0.027986000 & -6.195821000 & -2.417811000 \\
\hline 1 & 1.247532000 & 1.820200000 & 1.619257000 \\
\hline 1 & 1.332401000 & 3.098345000 & 2.817160000 \\
\hline 1 & -1.200701000 & 1.860865000 & 1.613689000 \\
\hline 1 & -1.206405000 & 3.136106000 & 2.843056000 \\
\hline 1 & -2.104676000 & 3.380289000 & 1.335328000 \\
\hline 1 & 1.200701000 & -1.860865000 & 1.613689000 \\
\hline 1 & 2.104676000 & -3.380289000 & 1.335328000 \\
\hline 1 & 1.206405000 & -3.136106000 & 2.843056000 \\
\hline 1 & -1.332401000 & -3.098345000 & 2.817160000 \\
\hline 1 & -1.247532000 & -1.820200000 & 1.619257000 \\
\hline 1 & 2.718953000 & 3.164329000 & 0.080124000 \\
\hline 1 & 2.774233000 & $4.46979500 \odot$ & 1.259079000 \\
\hline 1 & 3.904364000 & 2.932756000 & 2.913832000 \\
\hline 1 & 3.838950000 & 1.616990000 & 1.732416000 \\
\hline 1 & 4.830125000 & 3.048739000 & 1.409062000 \\
\hline 1 & -2.718953000 & -3.164329000 & 0.080124000 \\
\hline 1 & -2.774233000 & -4.469795000 & 1.259079000 \\
\hline 1 & -3.838950000 & -1.616990000 & 1.732416000 \\
\hline 1 & -4.830125000 & -3.048739000 & 1.409062000 \\
\hline 1 & -3.904364000 & -2.932756000 & 2.913832000 \\
\hline
\end{tabular}

$\mathrm{HF}=-1649.5789157$

\section{Ph-SQB*}

\begin{tabular}{|c|c|c|c|}
\hline 6 & $\odot .554905000$ & $-\odot .880494000$ & -1.305263000 \\
\hline 6 & 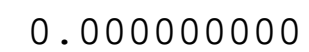 & 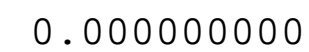 & $-0.24179400 \odot$ \\
\hline 6 & $-\odot .554905000$ & ๑.88049400९ & -1.305263000 \\
\hline 6 & $\odot . ๑ \odot \odot \odot \odot \odot \odot \odot \odot$ & ๑. $00000000 \odot$ & -2.31610200 \\
\hline
\end{tabular}




\begin{tabular}{|c|c|c|c|}
\hline 6 & 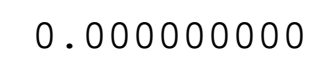 & ๑. .००००००००९ & -3.711661000 \\
\hline 8 & $\odot .000000000$ & ๑. . 000000000 & 0.983790000 \\
\hline 6 & -1.331131000 & 2.031706000 & -1.484245000 \\
\hline 6 & 1.331131000 & -2.031706000 & -1.484245000 \\
\hline 6 & -1.769514000 & 3. 010868000 & -0.603908000 \\
\hline 6 & 1.769514000 & -3.010868000 & -0.603908000 \\
\hline 6 & -1.500981000 & 3.225118000 & 0.896750000 \\
\hline 6 & -2.207578000 & 4.557037000 & 1.135659000 \\
\hline 6 & -2.838114000 & 4.969390000 & -0.041317000 \\
\hline 7 & -2.566871000 & 4. . 029229000 & -1.055435000 \\
\hline 7 & 2.566871000 & -4.029229000 & -1.055435000 \\
\hline 6 & 2.838114000 & -4.969390000 & -0.041317000 \\
\hline 6 & 2.207578000 & -4.557037000 & 1.135659000 \\
\hline 6 & 1.500981000 & -3.225118000 & $\odot .89675000 \odot$ \\
\hline 6 & -2.309698000 & 5.324420000 & $2.28568000 \odot$ \\
\hline 6 & -3.057621000 & 6.508604000 & 2.246573000 \\
\hline 6 & -3.688565000 & 6.906102000 & 1.065086000 \\
\hline 6 & -3.588490000 & 6.141880000 & -0.102563000 \\
\hline 6 & $3.58849000 \odot$ & -6.141880000 & -0.102563000 \\
\hline 6 & 3.688565000 & -6.906102000 & 1.065086000 \\
\hline 6 & 3.057621000 & -6.508604000 & 2.246573000 \\
\hline 6 & 2.309698000 & -5.324420000 & $2.28568000 \odot$ \\
\hline 6 & $3.07327900 \odot$ & -4.124251000 & -2.418863000 \\
\hline 6 & -3.073279000 & 4.124251000 & -2.418863000 \\
\hline 6 & 2.229927000 & -2.124277000 & 1.711729000 \\
\hline 6 & -2.229927000 & 2.124277000 & $1.71172900 \odot$ \\
\hline 6 & ๑ . .00000000 & -3.359738000 & 1.211328000 \\
\hline 6 & $\odot .000000 \odot \odot \odot$ & 3.359738000 & 1.211328000 \\
\hline 6 & $-\odot .58976000 \odot$ & -2.739462000 & 2.316957000 \\
\hline 6 & -1.938386000 & -2.949632000 & 2.616231000 \\
\hline 6 & -2.720036000 & -3.777781000 & 1.813193000 \\
\hline 6 & -2.142352000 & -4.398776000 & $\odot .703518000$ \\
\hline 6 & -0.796047000 & -4.193983000 & $\odot .411405000$ \\
\hline 6 & ๑. 796047000 & 4.193983000 & ๑. 411405000 \\
\hline 6 & 2.142352000 & 4.398776000 & $\odot .70351800 \odot$ \\
\hline 6 & 2.720036000 & 3.777781000 & 1.813193000 \\
\hline 6 & 1.938386000 & 2.949632000 & 2.616231000 \\
\hline 6 & 0.589760000 & 2.739462000 & 2.316957000 \\
\hline 6 & $\odot .627208000$ & -1.042634000 & -4.447926000 \\
\hline 7 & 1.150987000 & -1.914697000 & -5.022589000 \\
\hline 6 & -0.627208000 & 1.042634000 & -4.447926000 \\
\hline 7 & -1.150987000 & 1.914697000 & -5.022589000 \\
\hline 1 & -1.604224000 & $2.19802600 \odot$ & -2.519842000 \\
\hline 1 & 1.604224000 & -2.198026000 & -2.519842000 \\
\hline 1 & -1.806535000 & 5.017882000 & 3.198747000 \\
\hline 1 & -3.143629000 & 7.122533000 & 3.138182000 \\
\hline 1 & $-4.26512500 \odot$ & $7.8265300 \odot \odot$ & $1.04492400 \odot$ \\
\hline 1 & -4.080176000 & 6.468071000 & -1.013062000 \\
\hline 1 & 4.080176000 & -6.468071000 & -1.013062000 \\
\hline 1 & 4.265125000 & -7.826530000 & 1.044924000 \\
\hline 1 & $3.14362900 \odot$ & -7.122533000 & 3.138182000 \\
\hline
\end{tabular}




\begin{tabular}{|c|c|c|c|}
\hline 1 & 1.806535000 & $-5.01788200 \odot$ & 3.198747000 \\
\hline 1 & $2.25207900 \odot$ & -4.191297000 & $-3.13967000 \odot$ \\
\hline 1 & 3.675018000 & -3.2432660000 & $-2.66381800 \odot$ \\
\hline 1 & 3.696101000 & $-5.0129700 \odot \odot$ & $-2.50840400 \odot$ \\
\hline 1 & -3.675018000 & 3.243266000 & -2.663818000 \\
\hline 1 & -3.696101000 & $5.01297000 \odot$ & $-2.50840400 \odot$ \\
\hline 1 & $-2.25207900 \odot$ & $4.19129700 \odot$ & -3.139670000 \\
\hline 1 & $1.74389900 \odot$ & -1.156251000 & 1.578428000 \\
\hline 1 & $2.2265020 \odot \odot$ & -2.385212000 & $2.77494900 \odot$ \\
\hline 1 & 3.274977000 & -2.060483000 & 1.392312000 \\
\hline 1 & -1.743899000 & 1.156251000 & 1.578428000 \\
\hline 1 & $-2.22650200 \odot$ & $2.38521200 \odot$ & $2.77494900 \odot$ \\
\hline 1 & -3.274977000 & $2.06048300 \odot$ & 1.392312000 \\
\hline 1 & $-0.01141000 \odot$ & $-2.06848400 \odot$ & 2.939937000 \\
\hline 1 & $-2.37658800 \odot$ & -2.453418000 & 3.478253000 \\
\hline 1 & -3.769789000 & -3.936258000 & $2.04527400 \odot$ \\
\hline 1 & $-2.73902400 \odot$ & $-5.04462500 \odot$ & $\odot .064833000$ \\
\hline 1 & $-\odot .359471000$ & -4.690535000 & $-\odot .451506 \odot \odot \odot$ \\
\hline 1 & 0.359471000 & 4.690535000 & $-\odot .45150600 \odot$ \\
\hline 1 & $2.73902400 \odot$ & 5.044625000 & 0.064833000 \\
\hline 1 & 3.769789000 & 3.936258000 & $2.04527400 \odot$ \\
\hline 1 & 2.376588000 & 2.453418000 & 3.478253000 \\
\hline 1 & $\odot .01141000 \odot$ & 2.068484000 & 2.939937000 \\
\hline
\end{tabular}


In order to investigate the origin of the deviating optical properties of the phenyl-substituted squaraine derivatives, TDDFT calculations of Ph-SQB* using different geometries and substitution patterns at C(3) were performed. The results are summarized in Table S12.

Table S12. TD-DFT calculations of Ph-SQB* at B3LYP/6-31G*

\begin{tabular}{|l|l|l|l|}
\hline & $\begin{array}{l}\text { 证 } \\
\text { leV } \\
\text { (not } \\
\text { shifted) }\end{array}$ & $f$ & $R$ \\
\hline X-ray structure & 1.8251 & 0.3541 & 50.6 \\
\hline $\begin{array}{l}\text { planarity of } \pi \text { system } \\
\text { enforced }\end{array}$ & 1.8186 & 0.4323 & 45.5 \\
\hline \begin{tabular}{l} 
full DFT otimized \\
\hline $\begin{array}{l}\text { structure of full DFT } \\
\text { optimization but with } \\
\text { four Me groups at C(3) }\end{array}$
\end{tabular} & 1.9168 & 0.5103 & -3.4 \\
\hline
\end{tabular}

\section{References}

[1] Gawley, R. E. Do the Terms "\% ee" and "\% de" Make Sense as Expressions of Stereoisomer Composition or Stereoselectivity? J. Org. Chem. 2006, 71, 2411-2416.

[2] Sheldrick, G. M. A short history of SHELX. Acta Crystallogr. Sect. A 2008, 64, 112-122.

[3] Dolomanov, O. V.; Bourhis, L. J.; Gildea, R. J.; Howard, J. A. K.; Puschmann, H. OLEX2: a complete structure solution, refinement and analysis program. J. Appl. Crystallogr. 2009, 42, 339-341.

[4] Mayerhöffer, U.; Gsänger, M.; Stolte, M.; Fimmel, B.; Würthner, F. Synthesis and Molecular Properties of Acceptor-Substituted Squaraine Dyes. Chem. Eur. J. 2013, 19, 218-232.

[5] Schreck, M. H.; Breitschwerdt, L.; Marciniak, H.; Holzapfel, M.; Schmidt, D.; Würthner, F.; Lambert, C. fs-ps Exciton dynamics in a stretched tetraphenylsquaraine polymer. Phys. Chem. Chem. Phys. 2019, 21, 15346-15355.

[6] Lewis, J. E.; Maroncelli, M. On the (uninteresting) dependence of the absorption and emission transition moments of coumarin 153 on solvent. Chem. Phys. Lett. 1998, 282, 197-203.

[7] Schellman, J. A. Circular Dichroism and Optical Rotation. Chem. Rev. 1975, 75, 323331.

[8] Boros, S.; Gáspári, Z.; Batta, G., in Annual Reports on NMR Spectroscopy, Vol. 94 (Ed.: G. A. Webb), Academic Press, 2018, pp. 1-39. 
[9] Frisch, M. J.; Trucks, G. W.; Schlegel H. B.; Scuseria, G. E.; Robb, M. A.; Cheeseman, J. R.; Scalmani, G.; Barone, V.; Mennucci, B.; Petersson, G. A.; Nakatsuji, H.; Caricato,M.; Li, X.; Hratchian, H. P.; Izmaylov, A.F.; Bloino, J.; Zheng, G.; Sonnenberg, J. L.; Hada, M.; Ehara, M.; Toyota, K.; Fukuda, R.; Hasegawa, J.; Ishida, M.; Nakajima, T.;, Honda, Y.; Kitao, O.; Nakai, H.; Vreven, T.; Montgomery, J. A. Jr; Peralta, J. E.; Ogliaro, F.; Bearpark, M.; Heyd, J. J.; Brothers, E.; Kudin, K. N.; Staroverov, V. E.; Keith, T.; Kobayashi, R.; Normand, J.; Raghavachari, K.; Rendell, A.; Burant, J. C.; Iyengar, S. S.; Tomasi, J.; Cossi, M.; Rega, N.; Millam, J. M.; Klene, M.; Knox, J. E.; Cross, J. B.; Bakken, V.; Adamo, C.; Jaramillo, J.; Gomperts, R.; Stratmann, R. E.; Yazyev, O.; Austin, A. J.; Cammi, R.; Pomelli, C.; Ochterski, J. W.; Martin, R. L.; Morokuma, K.; Zakrzewski, V. G.; Voth, G. A.; Salvador, P.; Dannenberg, J.; Dapprich, S.; Daniels, A. D.; Farkas, O.; Foresman, J. B.; Ortiz, J. V.; Cioslowski, J.; Fox, D. J.; Gaussian, Inc., Wallingford CT, 2013. 